\title{
Simultaneous retrieval of aerosol and cloud properties during the MILAGRO field campaign
}

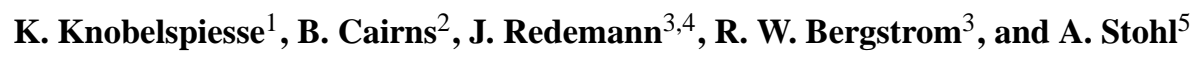 \\ ${ }^{1}$ NASA Postdoctoral Program Fellow, NASA Goddard Institute for Space Studies, New York, New York, USA \\ ${ }^{2}$ NASA Goddard Institute for Space Studies, New York, New York, USA \\ ${ }^{3}$ Bay Area Environmental Research Institute, Sonoma, California, USA \\ ${ }^{4}$ NASA Ames Research Center, Moffett Field, California, USA \\ ${ }^{5}$ Norwegian Institute for Air Research, Kjeller, Norway
}

Received: 28 January 2011 - Published in Atmos. Chem. Phys. Discuss.: 23 February 2011

Revised: 3 June 2011 - Accepted: 14 June 2011 - Published: 1 July 2011

\begin{abstract}
Estimation of Direct Climate Forcing (DCF) due to aerosols in cloudy areas has historically been a difficult task, mainly because of a lack of appropriate measurements. Recently, passive remote sensing instruments have been developed that have the potential to retrieve both cloud and aerosol properties using polarimetric, multiple view angle, and multi spectral observations, and therefore determine DCF from aerosols above clouds. One such instrument is the Research Scanning Polarimeter (RSP), an airborne prototype of a sensor on the NASA Glory satellite, which unfortunately failed to reach orbit during its launch in March of 2011. In the spring of 2006, the RSP was deployed on an aircraft based in Veracruz, Mexico, as part of the Megacity Initiative: Local and Global Research Observations (MILAGRO) field campaign. On 13 March, the RSP over flew an aerosol layer lofted above a low altitude marine stratocumulus cloud close to shore in the Gulf of Mexico. We investigate the feasibility of retrieving aerosol properties over clouds using these data. Our approach is to first determine cloud droplet size distribution using the angular location of the cloud bow and other features in the polarized reflectance. The selected cloud was then used in a multiple scattering radiative transfer model optimization to determine the aerosol optical properties and fine tune the cloud size distribution. In this scene, we were able to retrieve aerosol optical depth, the fine mode aerosol size distribution parameters and the cloud droplet size distribution parameters to a degree of accuracy required for climate modeling. This required assumptions
\end{abstract}

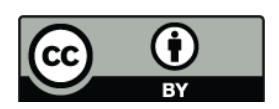

Correspondence to: $\mathrm{K}$. Knobelspiesse (kirk.d.knobelspiesse@nasa.gov) about the aerosol vertical distribution and the optical properties of the coarse aerosol size mode. A sensitivity study was also performed to place this study in the context of future systematic scanning polarimeter observations, which found that the aerosol complex refractive index can also be observed accurately if the aerosol optical depth is larger than roughly 0.8 at a wavelength of $(0.555 \mu \mathrm{m})$.

\section{Introduction}

The radiative effects of atmospheric aerosols (suspended particles) are among the least certain components of global climate models (IPCC, 2007). Even the most simple aerosol radiative effect, Direct Climate Forcing (DCF), is difficult to model, mainly due to the heterogeneity of aerosol sources, evolution, sinks, and radiative properties, and the difficulties of global observation (Mishchenko et al., 2009). DCF is defined as the change in net irradiance at the top of the atmosphere from the scattering and absorption of anthropogenic aerosols, and it neglects more complicated impacts due to aerosol induced changes in cloud properties or the atmospheric temperature vertical profile. Current modeling capability can be found in the results of the AeroCom model intercomparison effort. For example, Schulz et al. (2006) found a DCF range of +0.04 to $-0.41\left(\mathrm{~W} \mathrm{~m}^{-2}\right)$. A sensitivity analysis in this work found that DCF is strongly affected by aerosol forcing efficiency (the radiative forcing of a unit optical depth). Unfortunately, many factors that change aerosol forcing efficiency, such as particle size, absorption, and refractive index, are rarely observed to the level of accuracy required by climate models (Mishchenko et al., 2007b).

Published by Copernicus Publications on behalf of the European Geosciences Union. 
Furthermore, most aerosol remote sensing algorithms with passive instruments are successful only in cloudless conditions. Efforts to observe aerosols in the presence of clouds are still in their infancy, and are often intertwined with aerosol optical property assumptions.

The object of this study is the retrieval of aerosol properties when they are suspended above liquid boundary layer clouds. Aerosols above clouds (henceforth abbreviated as AAC) are a potentially important component of positive DCF, since absorbing AAC can significantly reduce a high underlying cloud albedo and therefore alter forcing (Haywood et al., 1997). However, reliable estimates of the global prevalence and anthropogenic component of this type of forcing are limited by a lack of appropriate observations, especially since DCF is strongly dependent on aerosol optical properties. Furthermore, AAC can interfere with the ability of passive instruments to accurately determine cloud optical properties (Coddington et al., 2010). Several approaches have been developed recently to observe AAC, but they are limited in their ability to distinguish aerosol types because of the significant assumptions required by their retrieval algorithms. Chand et al. (2008) used the active observations of the Cloud-Aerosol Lidar and Infrared Pathfinder Satellite Observations (CALIPSO) instrument to determine AAC optical depth at two wavelengths. The ratio of the optical depth spectral pair suggests the aerosol particle size. This method is therefore somewhat limited in its ability to determine DCF from AAC, although these type of data show promise in their potential for combined retrievals with passive remote sensing data. Another method uses passive spectrometer observations at ultra-violet wavelengths from instruments such as the Scanning Imaging Absorption Spectrometer for Atmospheric Chartography (SCIAMACHY). De Graaf et al. (2007) fit simulations of biomass burning (smoke) AAC to observations from the SCIAMACHY instrument to determine the aerosol total and absorbing optical thickness. An alternate technique, which we apply here, is to use multi-angle, multi-spectral, passive observations of polarized reflectance to simultaneously determine cloud and AAC optical properties. Waquet et al. (2009b) demonstrated this technique using data from the Moderate Resolution Imaging Spectroradiometer (MODIS) and the Polarization and Anisotropy of Reflectances for Atmospheric Sciences Coupled with Observations from a Lidar (PARASOL) instruments. Both instruments were a part of the so called "A-train" polar orbit until recently (January 2010), when the PARASOL instrument was moved to another orbit with the consumption of the fuel it needed to safely maintain its position. Waquet et al. (2009b) combined MODIS retrievals of cloud top height with PARASOL polarized observations at a variety of scattering angles to determine the aerosol optical thickness of biomass burning AAC in the South Atlantic Ocean. This required assumptions about the aerosol size and refractive index, since a single PARASOL band (at $0.865(\mu \mathrm{m})$ ) and a single scattering model were used. PARASOL also has a somewhat coarse angular resolution, which means observations over a large area must be collected in order to observe the cloud bow (which is similar to a rainbow, but is due to scattering from cloud, and not rain, droplets) with enough angular sampling to accurately constrain cloud optical properties. Nevertheless, we believe this approach has potential for future instruments that have a higher angular resolution and more available spectral bands than PARASOL.

The Aerosol Polarimetery Sensor (APS) is a scanning polarimeter was to be an instrument on the NASA Glory satellite (Mishchenko et al., 2007a). Unfortunately, Glory failed to reach orbit during its launch in March of 2011. Despite this setback, deployment of the APS airborne prototype, the Research Scanning Polarimeter (RSP) continues, and so does the analysis of the capabilities of this class of instrument. Both instruments are is intended to retrieve aerosol and cloud optical properties to a high degree of accuracy. They do so by gathering a large amount of information in each scene: solar reflected linear polarization at about 250 viewing angles in nine channels at visible and near infra-red wavelengths. Cloud and aerosol properties are retrieved by matching a doubling and adding radiative transfer model (Hansen and Travis, 1974) to observations. The Research Scanning Polarimeter (RSP), was developed to test APS observational capabilities (Cairns et al., 1997; Cairns, 2003). APS and RSP have very similar characteristics, where the latter has fewer view zenith angles (152) and slightly different center wavelengths for some bands. The RSP has flown on a variety of aircraft in many field campaigns. Field campaign data have been used to validate the ability of RSP/APS type instruments to observe aerosols over the ocean (Chowdhary et al., 2001; Chowdhary et al., 2002; Chowdhary et al., 2005a), aerosols over land (Elias et al., 2004; Waquet et al., 2009a), cloud optical properties (Chowdhary et al., 2005b), surface reflectance properties (Knobelspiesse et al., 2008; Litvinov et al., 2010), and of extremely optically thick plumes where the surface is obscured (Knobelspiesse et al., 2011).

In the spring of 2006, the RSP participated in a large field campaign called Megacity Initiative: Local and Global Research Observations (MILAGRO). The goal of MILAGRO was to examine the behavior, transport, and evolution of emissions from the Mexico City Metropolitan Area (MCMA). More than 450 scientists from 150 institutions participated, involving instrumentation onboard seven aircraft, multiple ground sites, and the coordinated use of atmospheric models and orbital observations (Molina et al., 2010). NASA's participation in MILAGRO was called the Intercontinental Chemical Transport Experiment-B (INTEXB), for which the RSP was deployed on the Sky Research, Inc., Jetstream-31 (J-31) aircraft. The J-31 was based in Veracruz, Mexico for three weeks in February and March, and performed a total of thirteen successful research flights. In addition to the RSP, several other instruments were part of the J-31 payload. This included the Ames Airborne Tracking Sunphotometer (AATS-14) (Redemann et al., 2009; 
Livingston et al., 2009), the Solar Spectral Flux Radiometer (SSFR) (Pilewskie et al., 2003; Bergstrom et al., 2010), the Cloud Absorption Radiometer (CAR) (Gatebe et al., 2010) and a Position and Orientation System (POS) and various meteorological sensors.

Aerosols encountered during MILAGRO were a complicated mix including urban/industrial particles from Mexico City (Doran et al., 2007; Lewandowski et al., 2010; Marley et al., 2009; Paredes-Miranda et al., 2009; Rogers et al., 2009 and others referenced in Molina et al. (2010)), smoke from local agricultural fires, and even volcanic sulfates (Grutter et al., 2008, de Foy et al., 2009). In the first two weeks of March, 2006, transport from the MCMA was weak but generally to the east, allowing aerosols to mix and age before they were transported over the Gulf of Mexico. On the morning of March 13th, a layer of low altitude (probably marine stratocumulus) clouds formed over the Gulf coast of Mexico between the cities of Veracruz and Tamiahua (approximately $96.75^{\circ} \mathrm{W}$ and $20.25^{\circ} \mathrm{N}$ ). The cloud slowly dissipated throughout the day, but was overflown by the J-31 aircraft, which later descended to the surface in a recently cloud free region. Observations by the SSFR and AATS-14 instruments on the J-31, along with aerosol transport model simulations, suggest that a layer of mixed aerosols were lofted above the cloud. This is therefore an ideal test scene for the ability of sensors such as RSP and APS to retrieve optical properties of AAC.

In the next section of this paper (2), we describe our methodology for the retrieval of AAC optical properties. Next (Sect. 3), we perform a short sensitivity study to help us construct an appropriate optimization strategy for AAC scenes. We then examine the retrieval results, and compare them with observations from other instruments on that day (Sect. 4). We also investigate the optimization sensitivity to forward model assumptions. We then discuss the implications of our retrieval and sensitivity studies on the ability of RSP and APS to resolve AAC optical properties in the context of climate model requirements (Sect. 5), followed by a brief conclusion.

\section{Method}

One benefit of multi-angle polarized measurements is that the various atmospheric components in a scene modify different angular portions of the observation. For our scene, where aerosols overlay a warm phase cloud, the cloud water droplet size distribution determines the angular location of the cloud bow (which typically exists at scattering angles somewhere around $142^{\circ}$ ) and the magnitude of secondary bows (Breon and Goloub, 1998). Aerosol properties such as optical depth, size distribution, and refractive index dominate the signal at side scattering angles less than $120^{\circ}$ (Goloub et al., 2000). Rayleigh scattering also contributes at these angles, which means multi-angle polarization observations
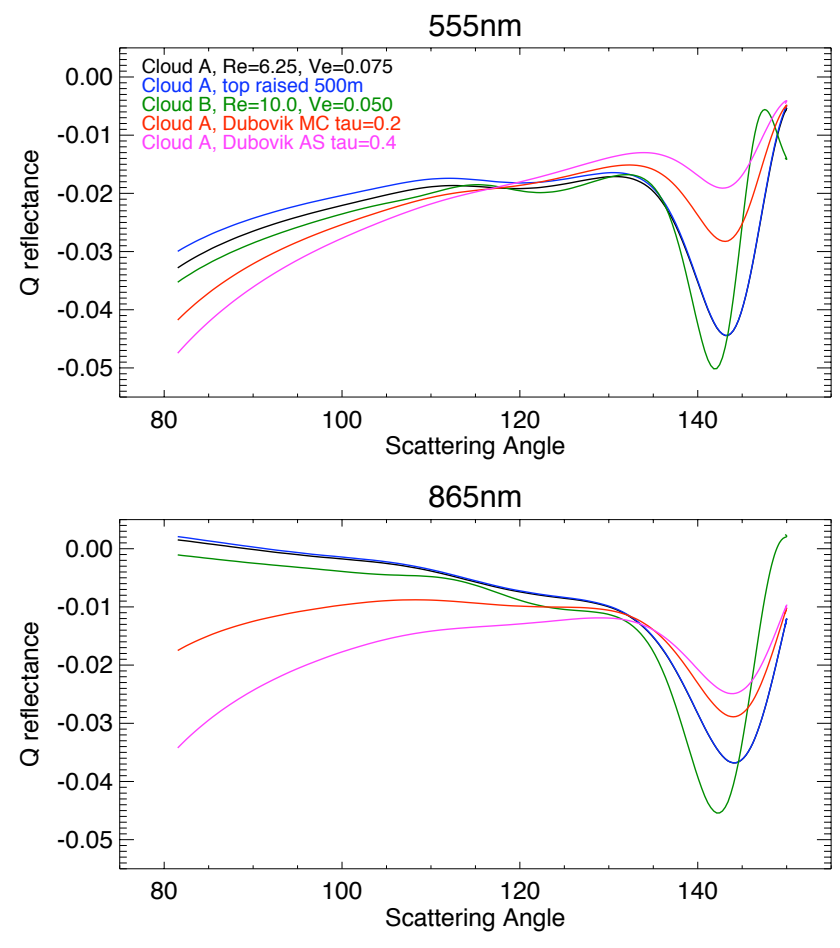

Fig. 1. The sensitivity of multi-angle polarimetry to cloud and aerosol optical properties is demonstrated in this figure. Black lines are $\left(R_{Q}\right)$ in the scattering plane for a simulated cloud (type A) with an optical thickness of 20.0 and a vertically uniform droplet size distribution of $\left(r_{e}=6.25 \mu \mathrm{m}\right),\left(v_{e}=0.75\right)$ from the ground to $480 \mathrm{~m}$. The top panel is reflectance at $0.555 \mu \mathrm{m}$, while the bottom panel is reflectance at $0.865 \mu \mathrm{m}$. Blue lines are reflectance from the cloud when the top has been raised by $500 \mathrm{~m}$. Green lines are the reflectance of a cloud containing different droplet sizes, $\left(\left(r_{e}=10 \mu \mathrm{m}\right),\left(v_{e}=0.05\right)\right)$. Red and magenta lines indicate the reflectance of a cloud with aerosols above, the former for "Mexico City" type urban aerosols with $(\tau(0.555)=0.2)$ and the latter for "African Savann" biomass burning aerosols with an optical thickness of $(\tau(0.555)=0.4)$ from Dubovik et al. (2002). All scenes are simulated with a solar zenith angle of $\left(\theta_{S}=45^{\circ}\right)$ and a relative azimuth angle of $\left(\phi=45^{\circ}\right)$.

can be used to determine cloud top heights in the absence of aerosols (Goloub et al., 1994). When aerosols are present, retrieval of their optical properties is helped by external information about the cloud top height. Figure 1 illustrates the available information in a synthetic AAC scene. This is expressed by $\left(R_{\boldsymbol{Q}}\right)$, which is defined below in Eq. (1). Note how the angular location of the cloud bow at high scattering angles changes with cloud droplet size distribution. Cloud top height has an impact at smaller scattering angles and the shorter wavelength, while AAC modify the magnitude of the cloud bow peak and alter the polarized reflectance at scattering angles less than $\left(120^{\circ}\right)$ for all wavelengths. 
In this paper, we test the capability of RSP to retrieve AAC optical properties. To do this, we start by identifying the cloud and aerosol vertical distribution using observations from other instruments on the J-31 aircraft. These are used to determine layer heights in a plane parallel radiative transfer model, which we iteratively modify to match to our observations using the Levenberg-Marquardt technique. The aerosol and cloud optical properties that create the best match are the "retrieved" values. Initial optical properties must be close to the retrieved solution and therefore selected with care. We find cloud initial values by matching observations of the cloud bow angular location and width to single scattering simulations (scattering phase functions computed with Mie theory). Aerosol initial values were selected from the "Urban-industrial and mixed; Mexico City" class described in Dubovik et al. (2002). This climatology was derived from a year of ground based measurements by the Aerosol Robotic Network (AERONET). The aerosol optical depth initial value comes from observations by the AATS-14 instrument during a spiral to the surface in a cloud free region near our scene.

The RSP observes the first three components of the Stokes polarization vector $((\boldsymbol{I}),(\boldsymbol{Q})$ and $(\boldsymbol{U}))$, meaning it is sensitive to both linearly polarized and total radiance (Hansen and Travis, 1974). For remote sensing, it is often useful to express the polarization components of the Stokes vector in terms of reflectance. This takes the exo-atmospheric radiance into account, and is calculated:

$$
\begin{aligned}
& R_{\boldsymbol{I}}=\frac{I \pi r_{o}^{2}}{F_{o} \cos \theta_{s}} \\
& R_{\boldsymbol{Q}}=\frac{Q \pi r_{o}^{2}}{F_{o} \cos \theta_{s}} \\
& R_{\boldsymbol{U}}=\frac{U \pi r_{o}^{2}}{F_{o} \cos \theta_{s}}
\end{aligned}
$$

where $\left(F_{o}\right)$ is the annual average exo-atmospheric irradiance $\left(\left(\mathrm{W} / \mathrm{m}^{2}\right)\right),\left(r_{o}\right)$ is the solar distance in AU (thus compensating for solar distance deviation from average throughout the year), and $\left(\theta_{S}\right)$ is the solar zenith angle. The RSP instrument has a high $(0.2 \%)$ absolute accuracy for $\left(R_{Q}\right)$ and $\left(R_{U}\right)$ relative to $\left(R_{I}\right)$, as the same detectors are used to measure intensity and linear polarization, and because calibration of their relative gain is performed with each scan. $\left(R_{U}\right)$ typically becomes very small when $(\boldsymbol{Q})$ and $(\boldsymbol{U})$ are defined with respect to the scattering plane (containing the solar illumination and observation vectors), so we subsequently use $\left(R_{Q}\right)$ defined in this plane as a proxy for total linear polarization. $\left(R_{U}\right)$ is only used to help correct for errors in aircraft geometry.

Our radiative transfer model uses Mie theory to compute the polarized phase functions (single scattering) for various types of aerosols or cloud droplets, and Rayleigh scattering for gases (for a historical review of Mie theory, see Mishchenko and Travis, 2008). This means we require a measure of cloud droplet size distribution, aerosol size distribution (which is typically bimodal) and the complex aerosol refractive index $((m=\Re(m)+\Im(m)))$, and that we assume the aerosols scatter like spheres. We express size distribution as an effective radius, $\left(r_{e}\right)$, and variance, $\left(v_{e}\right)$, where the former has units of microns and the latter is unitless (Hansen and Travis, 1974). Integrals of the size distribution are performed within a 0 to $20 \mu \mathrm{m}$ range. The size distribution of aerosols is typically bimodal, so we use the subscripts $(f)$ and $(c)$ to refer to fine and coarse mode aerosols. The former is usually the product of a chemical reaction, such as sulfate photo-oxidation or the production of biomass burning aerosols, and the latter is due to physical processes such as the creation of sea salt or dust aerosols. Cloud size parameters are denoted with the subscript $(\mathrm{cl})$. We use the lognormal distribution for aerosols and the gamma distribution for cloud droplets (equations 2.60 and 2.56 in Hansen and Travis (1974)). The complex refractive index, $(m)$, is set independently for each mode. In this work we assume the real part of $(\mathrm{m})$ is spectrally independent, while the imaginary component of the fine mode is specified with two parameters (see Sect. 2.4).

Once the single scattering properties for an aerosol or cloud droplet have been determined, multiple scattering is computed for the full atmosphere to create the polarized reflectance at the observation altitude. We use the Doubling and Adding technique (Hansen and Travis, 1974; De Haan et al., 1987), which assumes plane parallel layers of clouds and aerosols. The altitude of these layers are determined during the J-31 atmospheric profile as described in Sect. 2.2 and they are held constant in the optimization. The optical depth, $(\tau)$, of each layer is also required. As noted above, initial aerosol optical depth values are derived from the AATS-14. Cloud optical depth is set arbitrarily large $\left(\left(\tau_{\mathrm{cl}}(0.555 \mu \mathrm{m})=10.0\right)\right)$ to saturate the signal, since polarized reflectance is only sensitive to the first few units of cloud optical depth. Because of this, the surface is obscured and we assume its reflectance is negligible.

A complete list of the model values is presented in Table 1. Italicized parameters are allowed to vary during optimization and are thus retrieved, while other parameters are fixed and considered part of the radiative transfer model.

\subsection{AAC scene}

On 13 March 2006, the J-31 aircraft, containing the RSP and a variety of other instruments, departed from the Veracruz airport. The airplane flew northwest along the Gulf of Mexico coast and above a marine stratocumulus cloud. The cloud was in the process of dissipating, and it had a larger geographical extent earlier in the day (Bergstrom et al., 2010). Following the cloud overflight, the J-31 descended to the surface in a recently cloud free region. Figure 2 is a map of this scene, the descending spiral, and the surrounding area. We used observations that were made in that spiral profile to constrain cloud and aerosol layer heights in our scene, on the assumption that the atmospheric vertical profile had not 
Table 1. Retrieved aerosol parameters and the initial values used in optimization. Parameters listed in italics are optimized during the retrieval, while all others are kept constant. *: Refractive Index values have no spectral dependence in the initial values, although the spectral dependence of the fine mode aerosol imaginary component is allowed to vary as described in Sect. 2.4.

\begin{tabular}{lcc}
\hline Parameter & Symbol & Initial value \\
\hline Fine mode aerosols & & \\
Optical depth, $0.555 \mu m$ & $\tau_{f}(0.555)$ & 0.12 \\
Real refractive index & $\Re\left(m_{f}\right)$ & 1.47 \\
Imaginary ref. index, $0.555 \mu m^{*}$ & $\Im\left(m_{f}\right)$ & 0.014 \\
Imaginary refractive index, $p^{*}$ & $\Im\left(m_{f, p}\right)$ & 0.007 \\
Imaginary refractive index, $q^{*}$ & $\Im\left(m_{f, q}\right)$ & 0.007 \\
Effective radius, $(\mu \mathrm{m})$ & $r_{e, f}$ & 0.20 \\
Effective variance & $v_{e, f}$ & 0.20 \\
\hline Coarse mode aerosols & & \\
\hline Optical depth, $0.555 \mu \mathrm{m}$ & $\tau_{c}(0.555)$ & 0.04 \\
Real refractive index $(*)$ & $\Re\left(m_{c}\right)$ & 1.47 \\
Imaginary refractive index $(*)$ & $k_{c}$ & 0.014 \\
Effective radius $(\mu \mathrm{m})$ & $r_{e, c}$ & 7.67 \\
Effective variance & $v_{e, c}$ & 0.49 \\
\hline Cloud droplets & & \\
\hline Optical depth, $0.55 \mu \mathrm{m}$ & $\tau_{\mathrm{cl}}(0.555)$ \\
Effective radius $(\mu m)$ & $r_{\mathrm{e}, \mathrm{cl}}$ & 6.25 \\
Effective variance & $v_{\mathrm{e}, \mathrm{cl}}$ & 0.075 \\
\hline
\end{tabular}

changed dramatically in the $125 \mathrm{~km}$ distance between the observation location and descending spiral. Figure 3 is the temperature profile and vertical change in aerosol optical depth from this spiral. The temperature profile was used to determine the cloud top height $(480 \mathrm{~m})$ for our radiative transfer model, as shown in blue in Fig. 3. Change in aerosol optical depth (equivalent to the aerosol extinction coefficient), from the AATS-14 instrument, was used to constrain the AAC height $(550 \mathrm{~m}$ to $750 \mathrm{~m})$, shown in grey. Table 2 lists the geometry and other specifics associated with this scene and the downward spiral. A full description of this and other J31 flights during MILAGRO can be found in Molina et al. (2010).

\subsection{Aerosol sources}

The AAC we encountered in our scene were a complicated mixture with a variety of sources. Wind conditions on the 13th of March were light and variable, preceded by southwesterly winds associated with a trough over the western portion of the USA. This portion of the MILAGRO field campaign was characterized by low humidity and few cirrus clouds, and there were probable interactions between MCMA emissions and biomass burning smoke (Fast et al., 2007). Aerosols from a variety of sources were found during MILAGRO, including sulfates of both industrial and vol-
Table 2. Geometry and other parameters associated with our AAC scene, and the subsequent downward spiral. Aerosol optical depths are from the AATS instrument

\begin{tabular}{lc}
\hline Parameter & Value \\
\hline AAC scene & \\
\hline Starting Time & $16: 05 \mathrm{UTC}$ \\
J-31 altitude & $5380 \mathrm{~m}$ \\
Latitude & $20.15^{\circ} \mathrm{N}$ \\
Longitude & $96.68^{\circ} \mathrm{W}$ \\
Solar Zenith Angle & $44^{\circ}$ \\
Relative Azimuth Angle & $20^{\circ}$ \\
Number of averaged scans & 22 \\
\hline Downward Spiral & \\
\hline Starting Time & $16: 22 \mathrm{UTC}$ \\
J-31 altitude & 5360 to $51 \mathrm{~m}$ \\
Latitude & $21.06^{\circ} \mathrm{N}$ \\
Longitude & $96.95^{\circ} \mathrm{W}$ \\
Cloud top & $480 \mathrm{~m}$ \\
Aerosol layer bottom & $550 \mathrm{~m}$ \\
Aerosol layer top & $750 \mathrm{~m}$ \\
$(\tau 0.519 \mu \mathrm{m})$ above $550 \mathrm{~m}$ & 0.165 \\
$(\tau 0.604 \mu \mathrm{m})$ above $550 \mathrm{~m}$ & 0.130 \\
$(\tau 2.139 \mu \mathrm{m})$ above $550 \mathrm{~m}$ & 0.040 \\
\hline
\end{tabular}

canic origin (de Foy et al., 2009; Grutter et al., 2008), and organic carbon. Secondary organic carbon was more dominant than primary organic carbon, and was the result of both urban and (generally anthropogenic) biomass burning activities (Doran et al., 2007; Crounse et al., 2009; Yu et al., 2009; Paredes-Miranda et al., 2009). The MCMA is in a high valley ( $2200 \mathrm{~m}$ above sea level), so it is feasible for anthropogenic aerosols to be lofted above low level marine stratocumulus clouds on the coast.

This leads us to believe that the AAC aerosols in our scene are probably anthropogenic and that the fine size mode is the dominant contributor to scattering and absorption. To further investigate the aerosol sources, we used the FLEXPART Lagrangian particle dispersion model (Stohl et al., 2005) to determine the sensitivity of our scene to emission in other regions. Figure 4 is the footprint emission sensitivity obtained from FLEXPART driven by European Centre for Medium Range Weather Forecasts (ECMWF) meteorological data. Values of high emission sensitivity can be found both over the MCMA and biomass burning areas in the vicinity of Veracruz. However, results are somewhat different when the meteorology is driven by an alternate model, the Global Forecast System (GFS) from the National Center for Environmental Prediction (NCEP). FLEXPART driven by GFS shows an increased influence of Veracruz area smoke at the expense of MCMA pollution. This disparity is probably due to the weak and variable winds at that time, and indicates that the aerosols have had the opportunity to mix, 


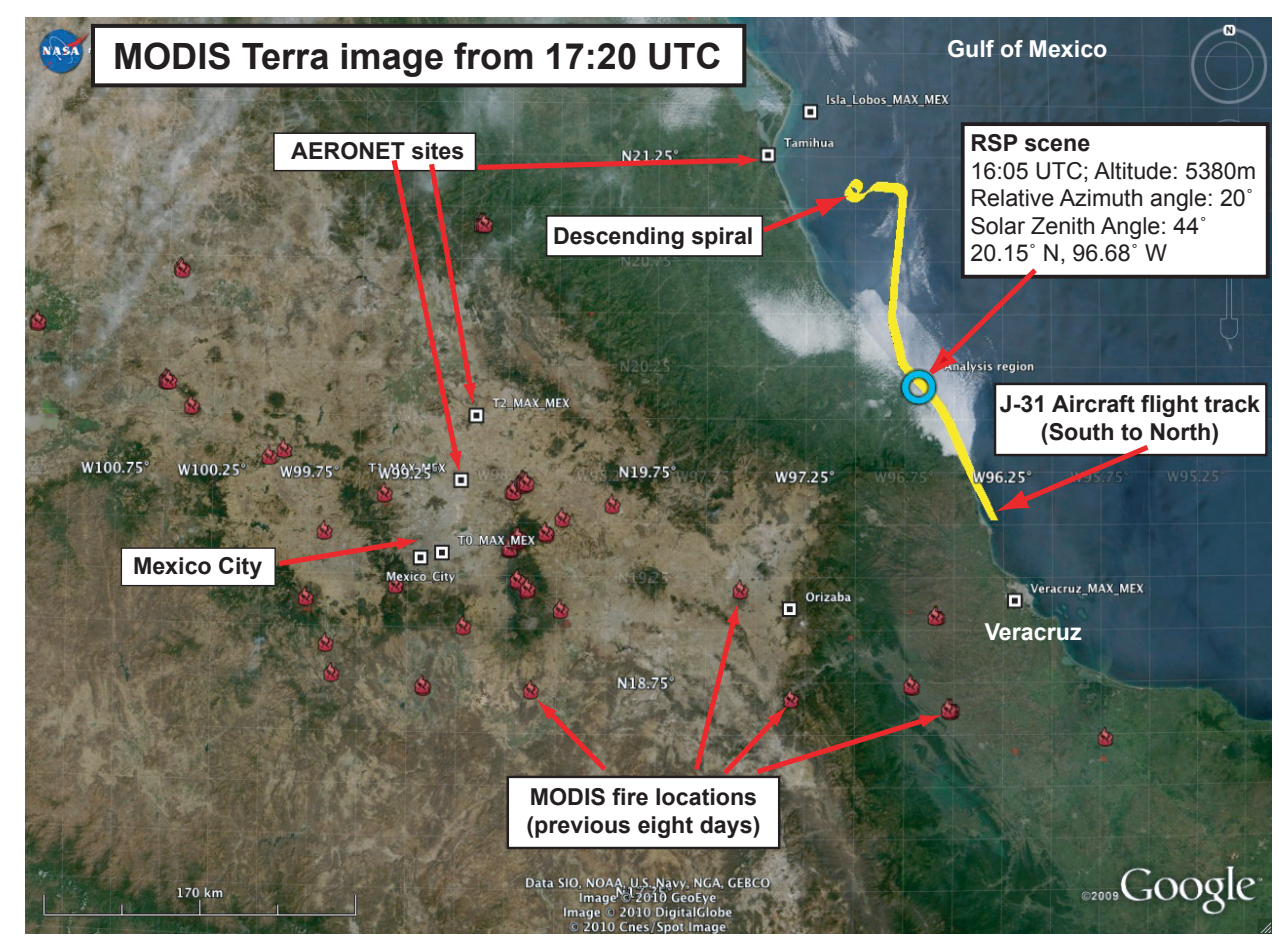

Fig. 2. The spatial context of our AAC scene is presented in this figure. The blue circle indicates the location of RSP observations, above a marine stratocumulus cloud on the Gulf of Mexico coast. A portion of the J-31 flight track is shown in yellow. The J-31 performed a spiral to the surface about $125 \mathrm{~km}$ northwest of the scene, and data collected during this descent provided information about cloud and aerosol vertical distribution. Aerosol sources include urban/industrial emissions in the Mexico City Metropolitan Area (MCMA) basin, a high valley to the west, and numerous (mostly agricultural) fires indicated by the red fire icons. Fire locations were identified by the MODIS active fire product and represent fires within the previous eight days. The MODIS Terra instrument captured the underlying image about an hour and fifteen minutes after our scene was observed.

accumulate, and age, with the exact distribution of contributing sources being somewhat more uncertain than for other cases.

\subsection{Determination of initial cloud size distribution}

Prior to performing our retrieval, we made an initial estimate of the cloud size distribution using a Look Up Table (LUT) of cloud droplet single scattering properties. Goloub, in his paper describing cloud property retrieval from the Polarization and Directionality of Earth Reflectances (POLDER) instrument (Goloub et al., 2000), found that polarization of cloud reflectances is less sensitive to multiple scattering than total reflectance. As cloud optical thickness becomes greater than $2,\left(R_{Q}\right)$ in the single scattering approximation becomes

$$
R_{\boldsymbol{Q}}\left(\theta_{s}, \theta_{v}, \xi\right)=\frac{1}{4\left(\cos \theta_{s}+\cos \theta_{v}\right)} Q\left(\xi, r_{\mathrm{e}, \mathrm{cl}}, v_{\mathrm{e}, \mathrm{cl}}\right)
$$

where $\left(\theta_{s}\right)$ is the solar zenith angle, $\left(\theta_{v}\right)$ is the view zenith angle and $(\boldsymbol{Q})$ is the Stokes vector component of the single scattering phase function. $(\xi)$ is the scattering angle, defined with respect to the incident illumination vector, and $\left(r_{\mathrm{e}, \mathrm{c}}\right.$, $\left.v_{\mathrm{e}, \mathrm{cl}}\right)$ are the cloud effective radius and variance.
At large scattering angles, where $\left(R_{\boldsymbol{Q}}\right)$ is dominated by the cloud signal (see Fig. 1), we can identify the cloud size distribution independently from cloud optical thickness or multiple scattering effects. $\left(R_{\boldsymbol{Q}}\right)$ is sensitive to cloud effective radius at scattering angles larger than $130^{\circ}$, and effective variance at angles larger than $145^{\circ}$ (Waquet et al., 2009b).

Our initial estimate of cloud size distribution is determined by matching $\left(R_{\boldsymbol{Q}}\right)$ to a LUT of $\left(\boldsymbol{Q}\left(\xi, r_{\mathrm{e}, \mathrm{cl}}, v_{\mathrm{e}, \mathrm{cl}}\right)\right)$ for a variety of size distributions. We used scattering angles between $135^{\circ}$ and $162^{\circ}$ (which was the largest scattering angle available in our scene). The LUT contained effective radii between 5 and $20 \mu \mathrm{m}$ at 0.25 intervals, and effective variances between 0.01 and 0.25 . Aerosol and molecular effects above the cloud are expressed in a manner that does not change rapidly with scattering angle (unlike the sharp cloud bow features), so we used a Fourier domain high pass filter (Gonzalez and Woods, 1992) to remove this low frequency signal prior to matching $\left(R_{Q}\right)$ to the LUT. To account for the possibility that absorbing AAC dampen the cloud signal, we allow both $\left(r_{\mathrm{e}, \mathrm{cl}}\right)$ and $\left(v_{\mathrm{e}, \mathrm{cl}}\right)$ to vary during optimization. 


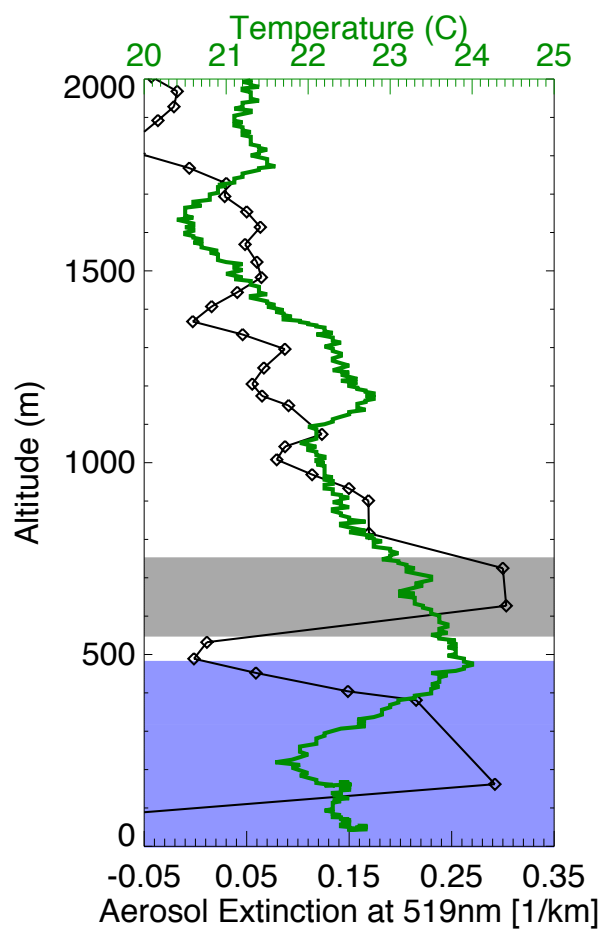

Fig. 3. The aerosol optical depth and temperature during the downward spiral northwest of our scene are presented in this figure. Optical depth observations were made by the AATS-14 instrument, and the derivative with respect to height (equivalent to the extinction coefficient) of observations at $0.519 \mu \mathrm{m}$ is presented in black. Two layers of aerosols are present. The lowest, between about 150 and $350 \mathrm{~m}$, was most likely not observable in our scene. The upper layer, between 550 and $750 \mathrm{~m}$, was probably above the cloud and therefore the same AAC that we observed in our scene. The atmospheric temperature profile is shown in green. At $48 \mathrm{~m}$, there is a sharp change in the temperature profile. This probably marks the upper boundary of the marine stratocumulus cloud that existed at this location several hours before. Based on this information, we constructed our radiative transfer model so that the cloud top is at $480 \mathrm{~m}$, with an aerosol layer above between 550 and $750 \mathrm{~m}$. The initial aerosol optical thickness value of the upper layer was estimated to be 0.16 at $0.555 \mu \mathrm{m}$ from AATS-14 data.

\subsection{Optimization}

Aerosol and cloud optical properties are retrieved by comparing a radiative transfer simulation of our scene to RSP observations, and tuning the model parameters until the best match is found. We use the Levenberg-Marquardt optimization technique as described in Moré (1977) and Markwardt (2009), and implemented for the RSP in Knobelspiesse et al. (2011). This means the retrieved parameters are not real numbers but regions of state space that are associated with the scene considering observational uncertainty. Waquet et al. (2009a) also used a similar approach with RSP data for aerosol retrievals over land.

\section{Footprint emission sensitivity in the nested domain for 2006/03/13 Lower release height: $500 \mathrm{~m}$; Upper release height: $750 \mathrm{~m}$ Meteorological data are from ECMWF}

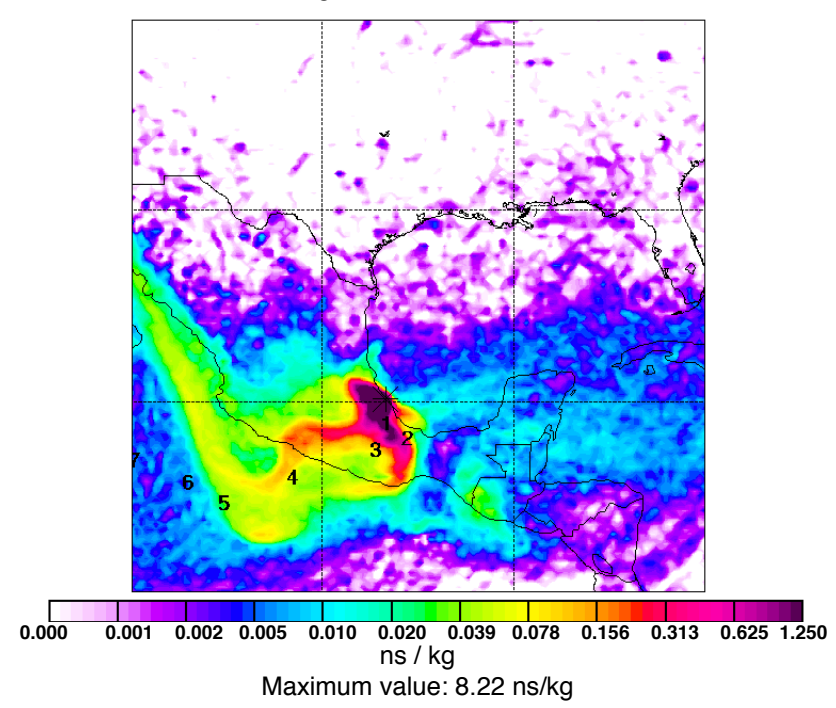

Fig. 4. Emission sensitivity footprint for the 500-750 m altitude range at our AAC scene obtained from FLEXPART driven by meteorological data from ECMWF.

We used the software developed in Knobelspiesse et al. (2011) for this study with slight modifications. First, we increased the numerical accuracy of the radiative transfer model. While computationally more expensive, this is required to properly simulate cloud droplets, which have much stronger forward scattering and produce more dramatic features than aerosols (such as cloud bows). We also modified the software so that the aerosol optical depth of a layer is a directly retrieved parameter. Previously, the total quantity of aerosols in a layer was determined by the particle number concentration, and this was the parameter that was tuned during optimization. Validation, however, is usually performed by comparisons of optical depth, since this is a common observation made by instruments such as sun photometers. While optical depth can of course be computed using the number concentration (and aerosol extinction cross section, which depends on size and refractive index), we switched to directly optimizing this parameter so that error computation is simpler. We also noticed that the optimization itself appears to require fewer iterations and is better behaved, although this observation is limited to this AAC scene.

We also modified the software in Knobelspiesse et al. (2011) to allow the imaginary component of the refractive index to have a spectral dependence. Rather than using the single value for each size mode, we now use a pair of parameters, $\left(\Im\left(m_{p}\right)\right)$ and $\left(\Im\left(m_{q}\right)\right)$ :

$\Im(m(\lambda))=\Im\left(m_{p}\right)+\Im\left(m_{q}\right)(\lambda+0.445)^{-10}$

where $(\lambda)$ is the wavelength in microns. This spectral dependence function is intended to allow for the increase in 
absorption at shorter wavelengths due to "brown carbon" (BrC, absorbing organic carbon aerosols). This was observed by the SSFR instrument on the same flight as our AAC scene (Bergstrom et al., 2010), which is our primary motivation for this change.

The choice of this form of specular dependence is unfortunately somewhat arbitrary, as direct observations of the imaginary refractive index of aerosols in their entirety are difficult and quite limited. Evidence of absorption in observations of the aerosol optical depth, on the other hand, are much more common. The absorption optical depth, $\left(\tau_{a}\right)$, which is the optical depth due to absorption (but not scattering) is generally characterized with the equation

$$
\tau_{a}(\lambda)=\tau_{a, o}\left(\lambda / \lambda_{o}\right)^{-\alpha}
$$

where $\left(\lambda_{o}\right)$ is a reference wavelength and $\left(\tau_{a, o}\right)$ is the absorption aerosol optical depth at that wavelength. $(\alpha)$ is the absorption Ångström Exponent, which should be equal to 1.0 for very small particles with spectrally invariant refractive indices (van de Hulst, 1981 and Bond, 2001). Larger Ångström Exponent values have been found in some biomass burning (smoke) aerosol plumes, such as in Lewis et al. (2008), indicating an increase in the imaginary refractive index (and thus absorption) at shorter wavelengths. Authors such as Hoffer et al. (2006) and Dinar et al. (2008) have found imaginary refractive indices that increase with decreasing wavelength for Humic-Like Substances (HULIS), which are likely components of $\mathrm{BrC}$, but direct observations of entire aerosol particles are limited. Others (Chen and Bond, 2010, Kirchstetter et al., 2004 and references therein) have found increasing aerosol absorption coefficients with shorter wavelength. While this is evidence of an increase in shortwave imaginary refractive index, the absorption coefficient is also dependent on particle size and real refractive index.

For small particles, the imaginary refractive index is proportional to wavelength and absorption coefficient $((\Im(m(\lambda)) \propto \lambda a))$ (Sun et al., 2007), which we use to connect our model for imaginary refractive index in equation 3 to observations. The $\left(\Im\left(m_{p}\right)\right)$ parameter indicates the quantity of spectrally independent absorption, while $\left(\Im\left(m_{q}\right)\right)$ expresses the quantity of spectrally dependent absorption. A large negative exponent has been selected so that variations in $\left(\Im\left(m_{p}\right)\right)$ and $\left(\Im\left(m_{q}\right)\right)$ have very different impacts, which allows their simultaneous retrieval during optimization, since they are more orthogonal in retrieval space. The exponent value of $(-10)$ was chosen from the upper limit to the absorption $\AA$ ngström Exponent found by Chen and Bond (2010). Spectral dependence is also shifted so that $\left(k(0.555)=\Im\left(m_{p}\right)+\Im\left(m_{q}\right)\right)$ and $(\Im(m(\lambda)))$ converges to $\left(\Im\left(m_{p}\right)\right)$ to as wavelength increases.

Figure 5 presents the imaginary refractive index that was retrieved in this work (in black, see Sect. 4), along with the imaginary refractive index models representing other scenes from Flowers et al. (2010) and Sun et al. (2007) (presented

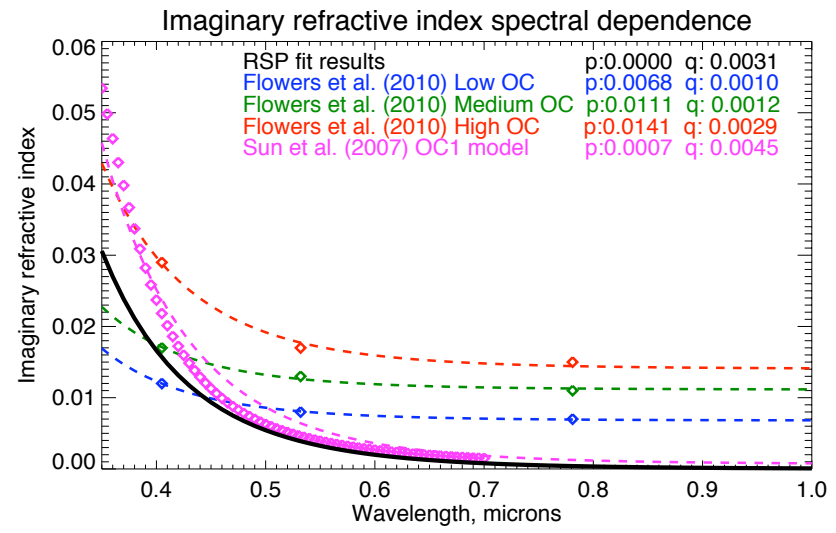

Fig. 5. Imaginary refractive index spectral dependence models from Flowers et al. (2010) (red, green and blue) and Sun et al. (2007) (magenta), compared to RSP retrieval results (black, see Sect. 4). Diamonds represent the published models, while dashed lines are the fit from equation 3 to that model.

as diamonds). Equation (3) was fit to these models, and is plotted as dashed lines in Fig. 5. Our imaginary refractive index parameterization is clearly capable of representing several types of refractive index models, and is therefore suitable for use during optimization.

Our optimization methods provide the retrieval error for each model parameter (see Sect. 3). Since it is not directly parameterized, the uncertainty in $(k)$ must be derived from the uncertainties in $\left(\Im\left(m_{p}\right)\right)$ and $\left(\Im\left(m_{q}\right)\right)$. Assuming that correlation between $\left(\Im\left(m_{p}\right)\right)$ and $\left(\Im\left(m_{q}\right)\right)$ is minimal, $\left(\sigma_{k}\right)$ for those parameters

$\sigma_{k}^{2}(\lambda)=\sigma_{k, p}^{2}+\sigma_{k, q}^{2}(\lambda+0.445)^{-20}$.

\section{Simulated aerosol above cloud}

To help us design an appropriate optimization strategy, we first assessed the information content available in an AAC scene. We did this by simulating a climatologically defined aerosol at a variety of optical depths suspended above a marine stratocumulus cloud. Other than optical depth, aerosol optical properties were chosen to match the "Mexico City Urban/Industrial" class described in Dubovik et al. (2002) and used as the initial value during optimization.

For each simulation, we numerically estimated the Jacobian matrix, $(\mathbf{J})$, which expresses the sensitivity of the forward model to change in each parameter,

$\mathbf{J}_{i j}(\mathbf{x})=\frac{\partial F_{i}(\mathbf{x})}{\partial x_{j}}$

where the artial derivative of forward model, $(\mathbf{F})$, for the simulated set of parameters, $(\mathbf{x})$, is computed for each observation $((i))$ and each parameter $((j))$. The partial derivative was estimated numerically by perturbing the $\left(j^{\text {th }}\right)$ element of 
(x) (which we denote as $\left(\mathbf{x}^{\prime}\right)$ ) and recalculating the forward model, $(\mathbf{F})$.

$J_{i j}(\mathbf{x}) \approx \frac{F_{i}\left(\mathbf{x}^{\prime}\right)-F_{i}(\mathbf{x})}{x_{j}^{\prime}-x_{j}}$

While the Jacobian is a useful metric to identify the relative importance of different parameters in measurement space, we are interested in parameter sensitivity. This is expressed with the retrieval error covariance matrix.

$\mathbf{C}_{x}=\left(\mathbf{J}^{T} \mathbf{C}_{T}^{-1} \mathbf{J}\right)^{-1}$

This requires the measurement error covariance matrix, $\left(\mathbf{C}_{T}\right)$, which is specific to the RSP and accounts for measurement uncertainty due to errors in calibration, and observation geometry. It is computed as in Eq. (3) of Knobelspiesse et al. (2011). The square root of the diagonal elements of $\left(\mathbf{C}_{x}\right)$ are the standard deviations of the errors for each parameter in $(\mathbf{x})$, provided that $\left(\mathbf{C}_{T}\right)$ is accurate and the forward model is linear over the perturbation range used to numerically calculate (J) (Hasekamp and Landgraf, 2007).

We simulated a scene very similar to the initial values we selected for optimization, with the exception of optical depth. Aerosol and cloud optical properties that were used for the simulation are listed in Table 1, while the cloud and aerosol vertical distribution is described in Table 2. Unlike our RSP scene, however, we selected a view zenith angle of $\left(45^{\circ}\right)$ and relative azimuth angle of $\left(45^{\circ}\right)$. This geometry was chosen to generalize the results for the APS, which will typically make observations farther from the solar principal plane (where $\left.\left(\phi=0^{\circ}\right)\right)$ than the RSP did in this scene. Observations in the solar principal plane contain more information than those at other relative azimuth angles because a larger range of scattering angles are measured. For this reason, we would expect lower errors for the RSP viewing geometry, although errors from brief simulations we performed at observational relative azimuth angles were nearly identical.

We performed two different sets of simulations. The first set simulated an optimization that used $\left(R_{\boldsymbol{Q}}\right)$ in seven RSP bands (centered at 0.410, 0.470, 0.555, 0.670, 0.865, 1.590 and $2.250 \mu \mathrm{m}$ ) at half degree intervals in the view zenith angle range of $\left( \pm 60^{\circ}\right)$ from nadir. At this geometry, the scattering angle range is from $\left(85^{\circ}\right)$ to $\left(150^{\circ}\right)$ and includes both side scattering angles (where aerosol properties dominate the signal) and the cloud bow (where cloud properties dominate the signal). The second simulation also used $\left(R_{Q}\right)$ at the wavelengths described above, but view angles restricted to $\left(20^{\circ}\right)$ to $\left(60^{\circ}\right)$ in the forward direction. The scattering angles that correspond with this are between $\left(85^{\circ}\right)$ and $\left(120^{\circ}\right)$, excluding the cloud bow. This is similar to the scattering angle range used to retrieve AAC properties in Waquet et al. (2009b), who was limited in his ability to determine cloud properties (due to the coarser angular resolution of POLDER) and performed an optimization using only observations where aerosol properties dominate.
Simulated retrieval errors are shown in Fig. 6. Aerosol remote sensing accuracy requirements for climate models, as assessed by Mishchenko et al. (2004), are also presented. These requirements were not determined for $\mathrm{AAC}$, but for retrievals of aerosols over land (without the presence of clouds) or clouds without aerosols above. We include them in Fig. 6 to compare the potential of AAC retrievals with the standard retrievals by the APS instrument for which these accuracy requirements were determined. For the full angular range simulation, these accuracy requirements are indeed met for aerosol optical depth, fine mode aerosol size, and cloud droplet size. Real refractive index and single scattering albedo requirements are not met, although errors decrease and nearly approach the requirements as aerosol optical depth increases. Errors for the simulation with fewer viewing angles are clearly higher. Aerosol optical depth accuracy requirements are no longer met, and errors for fine mode effective variance are too high at very low optical depths. Simulations also show sensitivity to cloud droplet size and effective variance within accuracy requirements for aerosol optical depths less than one. This is surprising considering that this simulation did not use observations of the cloud bow, where cloud properties should be dominant. These results, however, do not indicate the degree of correlation between different parameters in the retrieval. For the simulation with a total optical depth of $(\tau(0.555)=0.12)$, the cloud effective radius was strongly correlated with the fine mode optical depth and fine mode effective variance (see appendix A). Cloud effective variance was strongly correlated with the optical depth of both fine and coarse aerosols. These strong correlations do not exist for the equivalent retrieval that used the full angular range of observations.

These simulations suggest several strategies for successful optimization. The most obvious is that optimizations should utilize observations both of the cloud bow and side scattering angles. Cloud size parameters should be retrieved during optimization, since their assessed errors are low and those parameters are not significantly correlated with others (with one exception, see Appendix A). Furthermore, fine and coarse mode aerosol optical depth and fine mode size parameters can all be retrieved accurately. The real refractive index and absorption, however, are not retrieved accurately. Furthermore, those parameters have a high degree of correlation between themselves and with other parameters (see Appendix A). An ideal situation would be to have an accurate external measure of the aerosol complex refractive index that can be specified during optimization. Obviously, such measurements typically do not exist, so we are forced to consider retrieving some of the complex refractive index parameters, even if their retrieval error is larger than requirements for typical aerosol values. We are most interested in AAC absorption, since absorption is an important factor in the overall radiative forcing of AAC. The imaginary component of refractive index, however, is highly correlated with the optical depth of coarse mode aerosols. For 

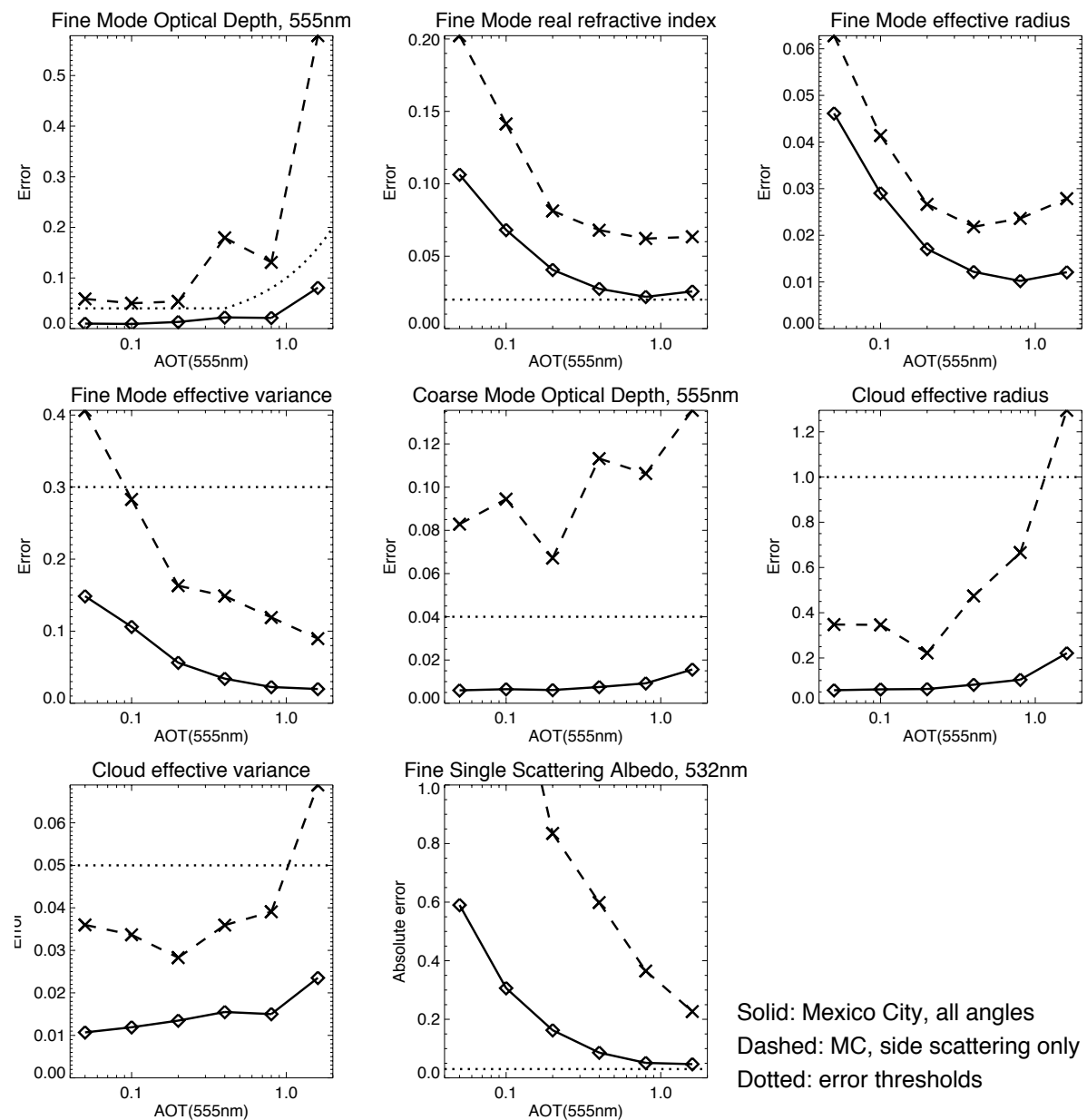

Fig. 6. Simulated retrieval error for "Mexico City" type aerosols (see Dubovik et al., 2002) suspended above a marine stratocumulus cloud. The aerosols, which were placed in a uniform layer between 550 and $750 \mathrm{~m}$ above sea level, were simulated at a variety of optical depths. The $\mathrm{x}$-axis of each plot is the fine mode aerosol optical depth at $0.555 \mu \mathrm{m}$. Coarse mode optical depth was maintained at $20 \%$ of the fine mode value for each simulation. The marine stratocumulus cloud had an effective radius of $\left(r_{\mathrm{e}, \mathrm{cl}}=6.25 \mu \mathrm{m}\right)$ and effective variance of $\left(v_{\mathrm{e}, \mathrm{cl}}=0.075\right)$, an optical depth of 10 , and was uniformly distributed (with respect to pressure) from the ground to $480 \mathrm{~m}$. Solid lines are the simulated errors for an observation including all view zenith angles within $\left(60^{\circ}\right)$ of nadir, which is similar to our scene and includes the cloud bow (and corresponds to a scattering angle range of $\left(85^{\circ}\right)$ to $\left(150^{\circ}\right)$ ). Dashed lines are the simulated errors for an optimization that only uses observations at angles between $\left(20^{\circ}\right)$ and $\left(60^{\circ}\right)$ in the forward direction, which excludes the cloud bow and is similar to the method of Waquet et al. (2009b), who had greater uncertainty when determining cloud parameters. These angles correspond to a scattering angle range of $\left(85^{\circ}\right)$ to $\left(120^{\circ}\right)$. Dotted lines are the accuracy thresholds described in Mishchenko et al. (2004) required to improve aerosol climate models. It is important to note that these values are intended for retrievals of aerosols in the absence of clouds or clouds in the absence of aerosols - not AAC. Also, the threshold for effective radius (top right) is $(0.1 \mu \mathrm{m})$, greater than all the simulated errors in that plot. The single scattering albedo (bottom, center) accuracy threshold is 0.03 , less than all simulated error values.

our optimization, we decided to fix the real refractive index at the climatological value for Mexico City aerosols as contained in Dubovik et al. (2002), while allowing both parameters describing the imaginary refractive index (see Sect. 2.4) to vary. Since the latter are correlated with coarse mode optical depth, we fixed that parameter to the optical depth observed by the AATS sun photometer at long wavelengths (where the coarse mode should contribute the most to overall extinction). Free parameters in our retrieval are therefore the aerosol fine mode optical depth, both parameters describing the imaginary component of fine mode refractive index, fine mode effective radius and variance, and cloud droplet effective radius and variance.

\section{Results}

\subsection{Cloud properties}

As described in Sect. 2.3, initial values for cloud droplet size were determined by matching a look up table of cloud droplet 


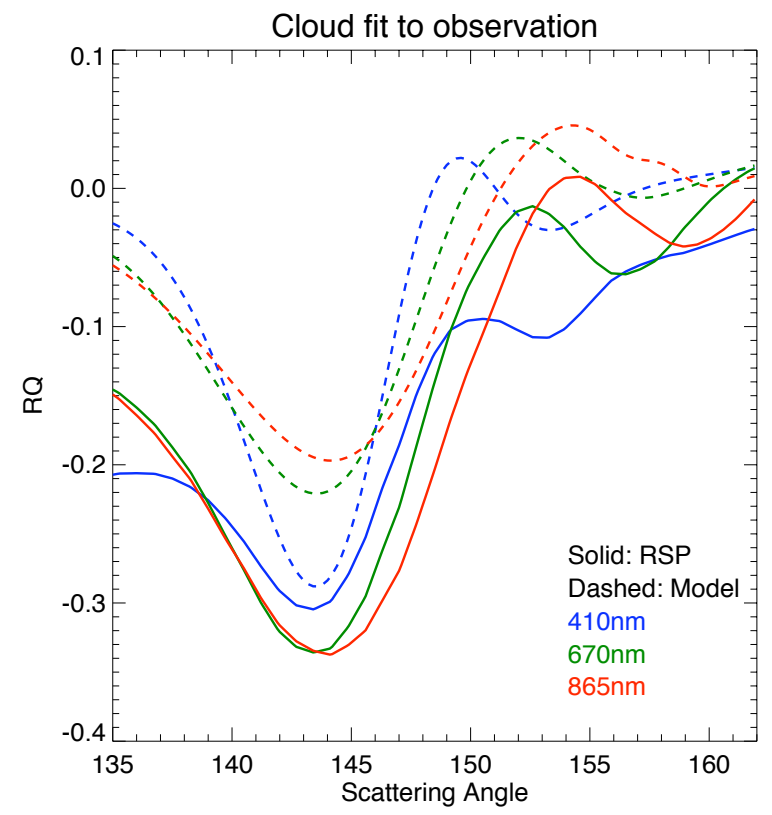

Fig. 7. RSP observations (solid lines) were matched to a look up table of cloud optical properties (dashed lines) to determine initial cloud droplet size properties for the optimization. The cloud that matched best had droplets with an effective radius of $\left(r_{\mathrm{e}, \mathrm{cl}}=\right.$ $6.25 \mu \mathrm{m})$ and effective variance of $\left(v_{\mathrm{e}, \mathrm{cl}}=0.075\right)$. Low frequency differences (bias) between cloud and RSP $\left(R_{Q}\right)$ are due to the effects of aerosols and Rayleigh scattering on the observation.

single scattering properties to observations. Because RSP observations also contain the effects of Rayleigh scattering and aerosols above the cloud, the cloud parameters determined with this method were allowed to vary in the next step, optimization. Here, aerosol and Rayleigh scattering effects were minimized by removing the low angular frequency trend before comparing the observation to the look up table. The best match was found for a cloud whose droplets have an effective radius of $\left(r_{\mathrm{e}, \mathrm{cl}}=6.25 \mu \mathrm{m}\right)$ and effective variance of $\left(v_{\mathrm{e}, \mathrm{cl}}=0.075\right)$. Fig. 7 shows this match (before low frequency trends are removed) for three wavelengths. While there are significant offsets between the RSP observation and cloud model, the angular location of the cloud bow in the data are well represented with the model.

\subsection{Aerosol and cloud simultaneous retrieval}

Optimization was performed using the data, methodology and initial values described above to retrieve seven aerosol and cloud parameters. Eleven iterations of the LevenbergMarquardt method were required to converge to a solution. Fig. 8 shows the radiative transfer model match to the observations, while table 3 is the aerosol and cloud parameters that were retrieved from the model. Comparisons between these results and observations made by other instruments are presented in Fig. 9.

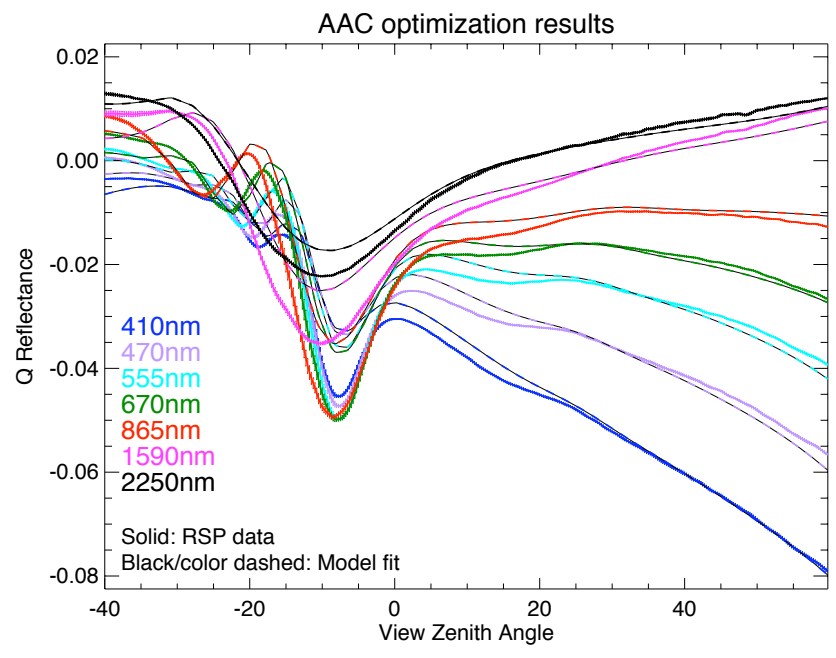

Fig. 8. RSP observations (solid lines), and the model match (dashed color/black lines) to those observations.

The optimized radiative transfer model appears to match best at forward scattering angles, where aerosol properties dominate. This is somewhat understandable in that the measurement error (as expressed in the error covariance matrix, $\left.\left(\mathbf{C}_{T}\right)\right)$ is smallest for these viewing angles. Measurement error is largest for cloud bow view zenith angles (between $\left(-20^{\circ}\right)$ and $\left.\left(0^{\circ}\right)\right)$ because of uncertainties in aircraft geometry that have the largest impact on features that change rapidly with angle. Perhaps as a result, model results are worst here, and underestimate the polarization in the cloud bow in all channels. However, we also found that few combinations of aerosol or cloud parameters could create such strong polarization in the cloud bow, indicating that our cloud model may be too simplistic. Regardless, aerosol and cloud parameter values have errors that are similar to those of the simulation in Sect. 3 for comparable optical depths. Aerosol optical depth and size parameters have low errors that meet the accuracy requirements of Mishchenko et al. (2004). There are no accuracy requirements for the aerosol imaginary refractive index, but the related single scattering albedo has an uncertainty so large as to render that parameter nearly useless. This is not much of a surprise, however, since the predicted error in single scattering albedo in the sensitivity test is comparable. The sensitivity test also shows that this error will decrease with increasing aerosol optical thickness, so that optical thicknesses above $(\tau(0.555)=0.8)$ have single scattering albedo errors nearly within accuracy requirements. The global radiative impact of these errors will therefore depend on the AAC optical thickness distribution.

The retrieved AAC properties show a somewhat thin (about half the climatological median optical thickness) layer of aerosols that have a fine mode effective radius very similar to the climatology of Dubovik et al. (2002). This is reasonable, however, because the observed altitudes represent 
Table 3. Retrieved aerosol and cloud parameters. *: These parameters are derived from other parameters, not directly retrieved. Errors in bold are larger than accuracy guidelines from Mishchenko et al. (2004) (note that guidelines were not provided in this publication for imaginary refractive index, and were not intended for AAC retrievals).

\begin{tabular}{lcccc}
\hline Symbol & Unit & Retrieval & Error & Simulation Error \\
\hline$\tau_{f}(0.555)$ & $\mathrm{n} / \mathrm{a}$ & 0.104 & 0.016 & 0.009 \\
$\tau(0.555)^{*}$ & $\mathrm{n} / \mathrm{a}$ & 0.144 & 0.016 & 0.009 \\
$\Im\left(m_{f, p}\right)$ & $\mathrm{n} / \mathrm{a}$ & 0.000 & 0.062 & 0.064 \\
$\Im\left(m_{f, q}\right)$ & $\mathrm{n} / \mathrm{a}$ & 0.003 & 0.036 & 0.015 \\
$\Im\left(m_{f}\right)(0.532)^{*}$ & $\mathrm{n} / \mathrm{a}$ & 0.004 & 0.077 & 0.063 \\
$r_{e, f}$ & $\mu \mathrm{m}$ & 0.143 & 0.007 & 0.029 \\
$v_{e, f}$ & $\mathrm{n} / \mathrm{a}$ & 0.057 & 0.036 & 0.106 \\
$r_{\mathrm{e}, \mathrm{cl}}$ & $\mu \mathrm{m}$ & 6.82 & 0.187 & 0.061 \\
$v_{\mathrm{e}, \mathrm{cl}}$ & $\mathrm{n} / \mathrm{a}$ & 0.028 & 0.009 & 0.012 \\
$\varpi(0.532)^{*}$ & $\mathrm{n} / \mathrm{a}$ & 0.868 & $\mathbf{0 . 4 5 0}$ & $\mathbf{0 . 3 0 6}$ \\
\hline
\end{tabular}

only a portion of the atmospheric column and do not include, for example, boundary layer aerosols. The width of the fine mode size distribution is quite small, which may be explained by the hypothesis in Bergstrom et al. (2010) that these aerosols have been cloud processed (although it should be noted that aerosol size distribution was not directly observed in that paper). The cloud droplet effective radius is close to, but slightly smaller than, the climatology for marine clouds in Miles et al. (2000). Compared to the initial values, the cloud effective radius increased slightly, while the effective variance decreased. This is somewhat understandable in light of the method used to determine the cloud initial size parameters. Aerosols and Rayleigh scattering above a cloud would generally be expected to attenuate the strong polarized signal emanating from the cloud bow. This would act to decrease the polarization strength of the cloud bow, and dampen the secondary oscillations associated with narrow size distributions. Once incorporated into a full multiple scattering radiative transfer model, the effects of droplet size on the observations are more accurately calculated, providing a better estimate of the droplet size distribution.

One interesting result from this optimization is that it converged to a solution where the $\left(\Im\left(m_{f, q}\right)\right)$ parameter is dominant, while $\left(\Im\left(m_{f, p}\right)\right)$ became nearly zero. Initial values for both these parameters were an equal split of $\left(\Im\left(m_{f}\right)\right)$ from the Dubovik et al. (2002) Mexico City climatology. Errors for both $\left(\Im\left(m_{f, p}\right)\right)$ and $\left(\Im\left(m_{f, q}\right)\right)$ are large, but this indicates a likely spectral dependence in the imaginary refractive index. This was also found by Bergstrom et al. (2010) in a nearby scene. We also tested optimizations that had spectrally flat initial conditions $\left(\left(\Im\left(_{f, p}\right)=0.014\right)\right.$ and $\left.\left(\Im\left(m_{f, q}\right)=0.0\right)\right)$, but they converged to what we found here, only with many more Levenberg-Marquardt iterations.
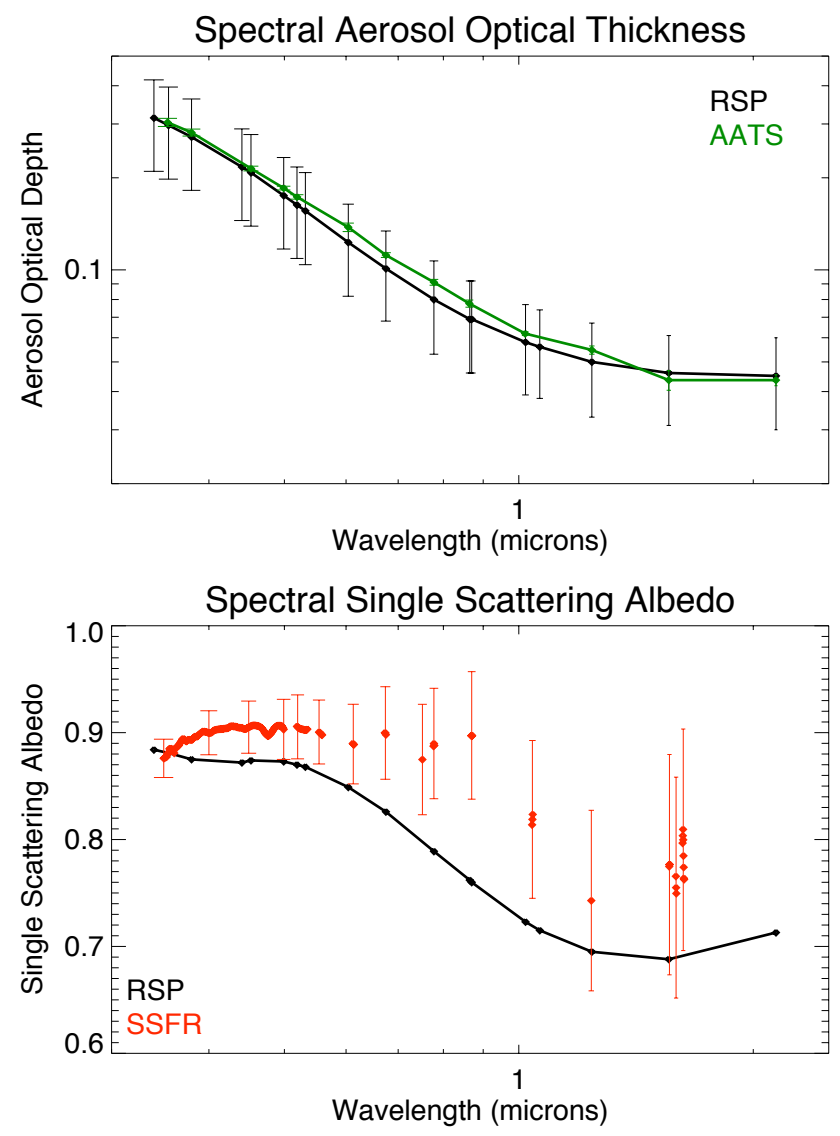

Fig. 9. The topmost panel in this figure is the spectral dependence of retrieved total aerosol optical thickness (black line) and the AATS observation (green line) at an altitude of $480 \mathrm{~m}$ during the downward spiral indicated in Fig. 2. The bottom panel is the spectral dependence of the total single scattering albedo. The black line is the RSP retrieved single scattering albedo, where the large error bars are omitted for clarity (they would fill the entire range of values in the plot). Red indicates SSFR observations as described in Bergstrom et al. (2010).

\subsection{Comparison with other observations}

Observations of the aerosol plume were also made by other instruments on the nJ-31 aircraft. The Ames Aerosol Tracking Sunphotometer (AATS) made observations of the spectral aerosol optical depth in a cloud free region about $125 \mathrm{~km}$ northwest of our scene. Aerosol absorption was also observed in this area by the Solar Spectral Flux Radiometer (SSFR) (Pilewskie et al., 2003; Schmidt et al., 2010), and published in Bergstrom et al. (2010) (see Fig. 2). As described in Sect. 2.2, atmospheric transport was weak prior to our observation, so we assume the aerosols at this location are similar to those in our AAC scene.

The aerosol optical thickness we retrieved agrees very well with AATS observations from an altitude of $480 \mathrm{~m}$ (which was the cloud top height in our AAC scene). To some extent, this is by design, since the longest wavelength AATS 
optical thickness values were used to constrain the AAC coarse mode aerosol optical thickness during optimization. Even so, at wavelengths less than $(0.8 \mu \mathrm{m})$, the majority of total aerosol optical thickness is determined by the fine mode, and AATS measurements at these wavelengths agree well within retrieval uncertainties.

The single scattering albedo that we retrieved has a very large uncertainty. However, comparisons with SSFR observations show some degree of similarity, at least for the shorter wavelengths of the spectrum. It is encouraging that agreement is better at these wavelengths since this is where the fine aerosol mode dominates extinction, and the imaginary refractive index of the fine mode was allowed to vary during optimization. Differences are greatest for the $(0.7 \mu \mathrm{m})$ to $(1.1 \mu \mathrm{m})$ wavelength range. The coarse aerosol mode contributes more to the total extinction at these wavelengths, but the imaginary refractive index for the coarse mode was held fixed during optimization. This may indicate that the coarse mode imaginary refractive index was not properly selected. Given the overall imaginary refractive index uncertainty, however, no firm conclusions can be made.

\subsection{Model uncertainty}

Forward model suitability is a major issue for optimizations such as this. Because of the finite information content available in our observations, we were required to make several assumptions about the nature of our scene. Many of these assumptions were based on external observations (such as the aerosol vertical distribution from AATS) or climatologies of aerosol properties (such as the coarse mode aerosol optical properties from Dubovik et al., 2002). While it is difficult to quantitatively assess these assumptions without further information, we can determine if the uncertainty in the data that went into making them has an impact on the retrieved parameter values. To do so, we start by modifying one of the assumptions in the forward model by its uncertainty, and recomputing with the retrieved parameters. The difference between this (which we will denote $(\hat{F}(\mathbf{x})))$ and the forward model results is the model error in measurement space. We can then use the Jacobian to project the error $((\mathbf{e}))$ into state space.

$\mathbf{e}=\left(\mathbf{J J}^{T}\right)^{-1} \mathbf{J}[\hat{F}(\mathbf{x})-F(\mathbf{x})]$

Table 4 contains values of (e) as a percentage of the retrieved parameter value for various model assumptions.

Model uncertainties come from a variety of sources. One class of model assumptions have to do with the physical description of the aerosol and cloud scene as plane parallel layers in a radiative transfer model. In this paper we test the validity of the vertical layering heights. Validity of the plane parallel model approach requires a comparison with a three dimensional radiative transfer model, which is beyond the scope of the current work and will be a topic of future research. Another class of assumptions has to do with the ge- ometry of the scene. While presumably this will not be an issue for orbital instruments, the aircraft carrying the RSP is subject to rapid attitude changes, so the measurement geometry does have uncertainty. Finally, we also test the assumptions we make about the aerosol optical properties we were not able to retrieve, such as the fine mode real refractive index and the coarse mode size and refractive index.

Aerosol and cloud layer tops were perturbed by the vertical resolution of the CALIPSO lidar (Winker et al., 2006 and Winker et al., 2003). CALIPSO is in the "A-Train" orbit, which was also the destination of the APS instrument. Operational retrievals of AAC from instruments similar to APS would likely use the cloud top height and aerosol vertical distribution from CALIPSO. Therefore, we used $30 \mathrm{~m}$ perturbations, which are equivalent to the vertical resolution of CALIPSO for the lower troposphere. It is clear that (e) for most retrieved parameters is not strongly affected by this level of uncertainty in the vertical distribution, although cloud layer top is more important than the aerosol vertical distribution. The imaginary refractive index for the fine mode does have a somewhat large degree of error. However, this error is much smaller than the retrieval error itself, which was about twenty times larger than the imaginary refractive index parameter value, and other model uncertainties have a much stronger effect on this parameter.

Proper knowledge of aircraft attitude is essential for accurate RSP retrieval. Aircraft attitude was provided by an Applanix POS-AV, which combines Global Positioning System technology with an inertial monitoring unit to determine position, velocity, pitch, roll and heading. There are of course limitations to the accuracy of such observations, and differences between the orientation of the POS-AV and the RSP instrument. To account for these errors, we modify our information about aircraft geometry using various features in the observed data. For example, $\left(R_{U}\right)$ should be minimal when defined with respect to the scattering plane for single scattering, so slight modifications to the aircraft pitch and yaw are made until this is the case. To understand the effect of geometric error, we perturbed the aircraft pitch and yaw angles by $\left(0.5^{\circ}\right)$. This choice was based on the sensitivity of our geometry correction techniques, but is probably an overestimate. The official POS-AV pitch accuracy is $\left(0.03^{\circ}\right)$, while yaw accuracy is $\left(0.1^{\circ}\right)$ (roll uncertainty is not accounted for in this work). Table 4 shows that uncertainty in aircraft yaw angle is not particularly important (although $\left(\Im\left(m_{f}\right)\right)$ uncertainty is large, as it is for many other model assumptions). Pitch angle uncertainty, however, has a significant impact on the ability to retrieve the fine mode aerosol effective variance, cloud droplet effective variance, and especially the cloud droplet effective radius. In fact, error in the cloud droplet effective radius is larger than the retrieved error for that parameter. Accurate retrievals of cloud droplet radius thus require accurate monitoring of instrument pitch angles. 
Table 4. This table contains the parameter sensitivity to changes in the forward radiative transfer model. This sensitivity is expressed as a percentage of the retrieved parameter value $((100 \times \mathbf{e} / \mathbf{x}))$. All of the parameter errors from model uncertainties are within the accuracy requirements of Mishchenko et al. (2004), and with one exception (the pitch angle uncertainty impact on the cloud effective radius, noted in bold), they are all less than the individual retrieval uncertainties.

\begin{tabular}{lcrrrrr}
\hline & $\tau_{f}(0.555)$ & $\Im\left(m_{f}\right)$ & $r_{e, f}$ & $v_{e, f}$ & $r_{\mathrm{e}, \mathrm{cl}}$ & $v_{\mathrm{e}, \mathrm{cl}}$ \\
\hline Aerosol layer top raised $30 \mathrm{~m}$ & $0.1 \%$ & $4.5 \%$ & $0.1 \%$ & $0.9 \%$ & $0.0 \%$ & $0.0 \%$ \\
Cloud layer top raised $30 \mathrm{~m}$ & $0.8 \%$ & $20.5 \%$ & $0.4 \%$ & $4.2 \%$ & $0.0 \%$ & $0.1 \%$ \\
Yaw angle changed by $\left(0.5^{\circ}\right)$ & $0.6 \%$ & $153.5 \%$ & $0.3 \%$ & $3.7 \%$ & $0.8 \%$ & $1.4 \%$ \\
Pitch angle changed by $\left(0.5^{\circ}\right)$ & $1.0 \%$ & $451.5 \%$ & $1.6 \%$ & $15.4 \%$ & $\mathbf{3 . 9 \%}$ & $6.0 \%$ \\
$\Re\left(m_{f}\right)$ increased by 0.02 & $6.9 \%$ & $57.8 \%$ & $2.6 \%$ & $12.1 \%$ & $0.0 \%$ & $0.2 \%$ \\
$\tau_{c}(0.555)$ increased by 0.02 & $4.0 \%$ & $1481.6 \%$ & $0.8 \%$ & $16.3 \%$ & $0.0 \%$ & $3.3 \%$ \\
$\Re\left(m_{c}\right)$ increased by 0.02 & $0.1 \%$ & $12.6 \%$ & $0.0 \%$ & $0.0 \%$ & $0.0 \%$ & $1.1 \%$ \\
$k_{c}$ increased by 0.006 & $0.9 \%$ & $9.1 \%$ & $0.0 \%$ & $1.6 \%$ & $0.1 \%$ & $1.7 \%$ \\
$r_{e, c}$ increased by 0.802 & $0.3 \%$ & $33.2 \%$ & $0.0 \%$ & $1.1 \%$ & $0.0 \%$ & $0.6 \%$ \\
$v_{e, c}$ increased by 0.093 & $0.2 \%$ & $44.3 \%$ & $0.0 \%$ & $1.0 \%$ & $0.1 \%$ & $0.6 \%$ \\
\hline
\end{tabular}

As shown in Sect. 3, the information available in RSP observations is not great enough to retrieve all optical properties for both aerosol modes. We therefore were required to assume some of these properties based on prior information. In this case, we used the fine mode real refractive index, and the coarse mode refractive index and size distribution from the Mexico City climatology of Dubovik et al. (2002). We used the climatological uncertainty for each assumed parameter to test our retrieval sensitivity. As we can see in Table 4, uncertainty in the assumed fine mode real refractive index value has a significant impact on the ability to retrieve fine mode optical depth, and a more moderate impact on fine mode size distribution. Considering the impact on aerosol optical thickness, the retrieval success for that parameter (see Fig. 9) indicates that the assumed real refractive index value was also valid. Coarse mode optical thickness was determined by longest wavelength observations by the AATS sun photometer. The assumption is that coarse mode aerosols, because of their size, have very little optical thickness spectral variation. Fine mode aerosols, on the other hand, have a very pronounced spectral dependence, and a nearly negligible optical thickness at long wavelengths. Optical depth observations at long wavelengths can therefore be assumed to represent the coarse mode only, and that value should be constant for all wavelengths. It is difficult to assess the uncertainty associated with this assumption, but we select a value of 0.02 , which is larger than the AATS uncertainty alone. Regardless, coarse mode aerosol uncertainty has a substantial effect on fine mode optical depth and effective variance, and a large effect on the fine mode imaginary refractive index. It appears that the selection of the coarse mode optical depth is important, so this must be done with care (or this parameter must be retrieved rather than assumed). Uncertainty in assumptions about the other coarse mode aerosol optical properties (complex refractive index and particle size distribution) have a minimal effect on retrieved parameter values, and can therefore be confidently assumed from climatologies.

\section{Discussion}

This research is a test of the capability of scanning polarimeters to retrieve the optical properties of aerosols lofted above clouds (AAC). The test was performed with observations from the airborne Research Scanning Polarimeter (RSP). The primary strategy for retrieving aerosol and cloud optical properties from RSP and APS is to match a multiple scattering radiative transfer model to observations by iteratively modifying model parameters until a match is found. The Levenberg-Marquardt method is used to perform this optimization. The software and tools that we used were developed in Knobelspiesse et al. (2011), which couples a publicly available Levenberg-Marquardt software with a Doubling and Adding type radiative transfer model.

An AAC scene observed by the RSP during the Megacity Initiative: Local and Global Research Observations (MILAGRO) field campaign was the primary source of data for this work. A mixture of urban industrial and agricultural biomass burning aerosols from central Mexico were lofted above a marine stratocumulus cloud close to shore over the western portion of the Gulf of Mexico. Several other instruments, including the Ames Airborne Tracking Sunphotometer (AATS14) and the Solar Spectral Flux Radiometer (SSFR) were onboard this aircraft, and collected data that were used to either guide the AAC optimization or validate the results.

This research had three main sections. First, we simulated the RSP/APS retrieval error for an AAC scene with climatologically defined aerosol properties (Dubovik et al., 2002) at a variety of optical depths. We found that the aerosol optical depth, fine mode aerosol size distribution, and cloud droplet size distribution can all be retrieved for an AAC scene to the accuracy requirements for climate modeling in Mishchenko et al. (2004). Aerosol refractive index simulated errors are much higher. The error in the real component of the refractive index decreases with increasing aerosol optical depth, and approach accuracy requirements as optical depth 
Table 5. Correlation matrix for a simulated AAC scene with $\left(\tau_{f}(0.555)=0.1\right)$ and an optimization utilizing angles within $\left(60^{\circ}\right)$ of nadir. Elements with absolute values greater than 0.5 , indicating strong correlation, are in bold.

\begin{tabular}{|c|c|c|c|c|c|c|c|c|c|}
\hline & $\tau_{f}(0.555)$ & $\Re\left(m_{f}\right)$ & $\Im\left(m_{f, p}\right)$ & $\Im\left(m_{f, q}\right)$ & $r_{e, f}$ & $v_{e, f}$ & $\tau_{c}(0.555)$ & $r_{\mathrm{e}, \mathrm{cl}}$ & $v_{\mathrm{e}, \mathrm{cl}}$ \\
\hline$\tau_{f}(0.555)$ & 1.00 & & & & & & & & \\
\hline$\Re\left(m_{f}\right)$ & -0.36 & 1.00 & & & & & & & \\
\hline$\Im\left(m_{f, p}\right)$ & 0.26 & 0.44 & 1.00 & & & & & & \\
\hline$\Im\left(m_{f, q}\right)$ & -0.42 & 0.27 & -0.55 & 1.00 & & & & & \\
\hline$r_{e, f 4}$ & 0.49 & -0.96 & -0.35 & -0.30 & 1.00 & & & & \\
\hline$v_{e, f}$ & -0.10 & 0.64 & 0.00 & 0.32 & -0.68 & 1.00 & & & \\
\hline$\tau_{c}(0.555)$ & -0.40 & -0.45 & -0.53 & 0.30 & 0.33 & -0.38 & 1.00 & & \\
\hline$r_{\mathrm{e}, \mathrm{cl}}$ & 0.02 & 0.08 & 0.07 & -0.01 & -0.01 & -0.01 & -0.00 & 1.00 & \\
\hline$v_{\mathrm{e}, \mathrm{cl}}$ & -0.17 & -0.05 & -0.68 & 0.30 & 0.03 & 0.24 & 0.01 & 0.09 & 1.00 \\
\hline
\end{tabular}

Table 6. Correlation matrix for a simulated AAC scene with $\left(\tau_{f}(0.555)=0.1\right)$ and an optimization utilizing angles $\left(20^{\circ}\right)$ and $\left(60^{\circ}\right)$ forward of nadir. Elements with absolute values greater than 0.5 , indicating strong correlation, are in bold.

\begin{tabular}{|c|c|c|c|c|c|c|c|c|c|}
\hline & $\tau_{f}(0.555)$ & $\mathfrak{R}\left(m_{f}\right)$ & $\Im\left(m_{f, p}\right)$ & $\Im\left(m_{f, q}\right)$ & $r_{e, f}$ & $v_{e, f}$ & $\tau_{c}(0.555)$ & $r_{\mathrm{e}, \mathrm{cl}}$ & $v_{\mathrm{e}, \mathrm{cl}}$ \\
\hline$\tau_{f}(0.555)$ & 1.00 & & & & & & & & \\
\hline $\mathfrak{K}\left(m_{f}\right)$ & 0.44 & 1.00 & & & & & & & \\
\hline$\Im\left(m_{f, p}\right)$ & 0.63 & 0.18 & 1.00 & & & & & & \\
\hline$\Im\left(m_{f, q}\right)$ & -0.41 & -0.24 & -0.73 & 1.00 & & & & & \\
\hline$r_{e, f}$ & 0.10 & -0.82 & 0.06 & 0.12 & 1.00 & & & & \\
\hline$v_{e, f}$ & 0.38 & 0.74 & -0.31 & 0.16 & -0.51 & 1.00 & & & \\
\hline$\tau_{c}(0.555)$ & -0.90 & -0.64 & -0.61 & 0.40 & 0.15 & -0.42 & 1.00 & & \\
\hline$r_{\mathrm{e}, \mathrm{cl}}$ & -0.70 & -0.28 & -0.11 & 0.06 & -0.12 & -0.55 & 0.49 & 1.00 & \\
\hline$v_{\mathrm{e}, \mathrm{cl}}$ & 0.71 & 0.25 & 0.24 & -0.10 & 0.19 & 0.39 & -0.62 & -0.45 & 1.00 \\
\hline
\end{tabular}

at $(0.555 \mu \mathrm{m})$ exceeds 0.8 . Aerosol single scattering albedo error (and the imaginary part of the refractive index from which it based) also decrease with increasing optical depth to values approaching accuracy requirements. Simulations also show that it is preferable to retrieve aerosol properties and cloud droplet size distributions simultaneously using all available angle observations, rather than to separate the two and retrieve cloud droplet properties from observations of the cloud bow and aerosol optical properties from observations at side scattering angles. We then performed an optimization for an example AAC scene. This optimization successfully converged to a solution, where a thin layer of aerosols overlay a marine stratocumulus cloud made up of relatively small sized droplets. Errors for this optical depth were quite similar to the predictions using simulated data. The retrieved aerosols appear similar to the climatology for Mexico City aerosols in Dubovik et al. (2002), although with a narrow size distribution range possibly associated with particle humidification or cloud processing. We found evidence of an increase in absorption for the shortest wavelengths, which is a likely due to Brown Carbon aerosols and was also observed by Bergstrom et al. (2010) for the same aerosols. However, the imaginary refractive index retrieval uncertainty (which determines aerosol absorption) is extremely large. While this was predicted with the scene simulations for aerosols with a thin optical depth, it limits any conclusions that can be drawn from these results. Nonetheless, optical depth and single scattering albedo results compare favorably with measurements by other instruments. Finally, we assessed the importance of uncertainty in various model components. We found that the aerosol and cloud layer height resolution as provided by the CALIPSO instrument will be sufficient for AAC retrievals by scanning polarimeters in orbit. Accurate measurements of aircraft geometry, especially pitch, are important for retrievals with airborne instruments such as the RSP data. Finally, while the coarse mode optical depth has a strong effect on retrieval uncertainty, assumptions about other coarse mode aerosol optical properties only have a small effect on the fine mode properties that are being retrieved.

This work suggests that scanning polarimeters are capable of retrieving the total aerosol optical depth, fine mode size distribution, and cloud droplet size distribution for aerosols lofted above clouds. This is true provided that the scene can be simulated as plane layers within the observed pixel, and that the layer heights can be supplied by external observations (such as the CALIPSO lidar). Fine mode aerosol 
refractive index retrievals have a high error that decreases with increasing AAC optical depth. These errors approach modeling requirements as optical depths approach and exceed about 0.8 at a wavelength of $(0.555 \mu \mathrm{m})$. Most AAC optical depths will probably not be that large. For lower optical depths, we may need to fix refractive index values using a climatology or external measurements, or use an optimization method such as Philips Tikhonov regularization (Hasekamp, 2010). The retrieved optical depth will be sensitive to the accuracy of that assumption. Considering this dependency, an alternate approach might be to fix the optical depth (since observations of optical depth are much more common than those of refractive index), and allow refractive index parameters to vary. We did not attempt this technique in this work, but it may be a worthwhile approach in the future, if the RSP or APS are observing in coordination with lidars such as the High Spectral Resolution Lidar (HSRL), which retrieve both aerosol vertical distribution and aerosol optical depth (Hair et al., 2001; Hair et al., 2008; Rogers et al., 2009).

\section{Conclusions}

The direct radiative effect of aerosols suspended above clouds (AAC) are a potentially important but rarely observed phenomenon. Scanning polarimeters, such the Research Scanning Polarimeter (RSP), have the capability to retrieve AAC properties using nonlinear optimization methods that match a radiative transfer model to instrument observations. In this paper, we tested the capability of such a retrieval using RSP observations of a mixed urban and agricultural fire smoke aerosol above a marine stratocumulus cloud in the western portion of the Gulf of Mexico. Provided that the vertical structure of the cloud and aerosol are known, the aerosol optical depth, cloud droplet size distribution and aerosol fine size mode size distribution can be retrieved. Reasonable values were found for the complex refractive index of the fine aerosol size mode, but their associated uncertainty is large. We also performed a sensitivity study for a similar scene at a variety of AAC optical depths, and found that uncertainties decrease as optical depth increases. If the aerosol optical depth exceeds roughly 0.8 at a wavelength of $(0.555 \mu \mathrm{m})$, refractive index uncertainties decrease to a degree that is almost sufficiently accurate for the needs of climate models. Once launched, the APS will be able to provide much more information about AAC than was previously available. However, the complex refractive index will be limited in its accuracy unless external data can be used as a constraint or the aerosol optical depth is unusually large.

\section{Appendix A}

\section{Correlation in simulations}

The analysis in Sect. 3 describes the parameter sensitivity of the retrieval, but does not express the correlations between the parameters. The off diagonal elements of $\left(\mathbf{C}_{x}\right)$ (equation 8) can be used for this purpose if they are normalized by the parameter error to create the correlation matrix

$\rho_{i j}=\frac{\mathbf{C}_{x, i j}}{\sqrt{\mathbf{C}_{x, i i}} \sqrt{\mathbf{C}_{x, j j}}}$

Tables 5 and 6 are the correlation matrices for the $\left(\tau_{f}(0.555)=0.1\right)$ simulations in Sect. 3 .

Acknowledgements. The first author acknowledges support from the US National Science Foundation, through a Fellowship in the IGERT Joint Program in Applied Mathematics and Earth and Environmental Science at Columbia University at the time of the MILAGRO field campaign. His graduate studies were also funded by the NASA Glory project. Currently, he is supported by an appointment to the NASA Postdoctoral Program at the NASA Goddard Institute for Space Studies, administered by Oak Ridge Associated Universities through a contract with NASA. RSP participation during the MILAGRO field campaign was funded by the NASA Radiation Sciences Program, managed by Dr. Hal Maring. MODIS imagery was provided by the NASA GSFC Rapid Response System. Thanks to the many who helped collect the data used in this study: Edgar Russell was the RSP engineer, Ben Hovelman was the J-31 pilot, Roy Johnson and Nicholas Truong were AATS-14 engineers, Rose Dominguez provided J-31 Navigational and GPS data, and Warren Gore provided J-31 Meteorological data. Finally, thanks to Andy Ackerman and Mikhail Alexandrov for their advice about cloud optical properties during the preparation of this manuscript.

Edited by: L. Molina

\section{References}

Bergstrom, R. W., Schmidt, K. S., Coddington, O., Pilewskie, P., Guan, H., Livingston, J. M., Redemann, J., and Russell, P. B.: Aerosol spectral absorption in the Mexico City area: results from airborne measurements during MILAGRO/INTEX B, Atmos. Chem. Phys., 10, 6333-6343, doi:10.5194/acp-10-63332010, 2010.

Bond, T.: Spectral dependence of visible light absorption by carbonaceous particles emitted from coal combustion, Geophys. Res. Lett., 28, 4075-4078, 2001.

Breon, F. and Goloub, P.: Cloud droplet effective radius from spaceborne polarization measurements, Geophys. Res. Lett., 25, 1879-1882, 1998.

Cairns, B.: Polarimetric Remote Sensing of Aerosols, IEEE Trans. Geosci. Remote Sens., 518-520, 2003.

Cairns, B., Travis, L., and Russell, E.: An analysis of polarization: ground based upward looking and aircraft/satellite based downward looking measurements, in: Satellite Remote Sensing of Clouds and the Atmosphere II, SPIE, 1997. 
Chand, D., Anderson, T., Wood, R., Charlson, R., Hu, Y., Liu, Z., and Vaughan, M.: Quantifying above-cloud aerosol using spaceborne lidar for improved understanding of cloudysky direct climate forcing, J. Geophys. Res, 113, D13206; doi:10.1029/2007JD009433, 2008.

Chen, Y. and Bond, T.: Light absorption by organic carbon from wood combustion, Atmos. Chem. Phys, 10, 1773-1787, doi:10.5194/acp-10-1773-2010, 2010.

Chowdhary, J., Cairns, B., Mishchenko, M., and Travis, L.: Retrieval of aerosol properties over the ocean using multispectral and multiangle photopolarimetric measurements from the Research Scanning Polarimeter, Geophys. Res. Lett., 28, 243-246, 2001

Chowdhary, J., Cairns, B., and Travis, L.: Case Studies of Aerosol Retrievals over the Ocean from Multiangle, Multispectral Photopolarimetric Remote Sensing Data, J. Atmos. Sci., 59, 383397, 2002.

Chowdhary, J., Cairns, B., Mishchenko, M., Hobbs, P., Cota, G., Redemann, J., Rutledge, K., Holben, B., and Russell, E.: Retrieval of Aerosol Scattering and Absorption Properties from Photopolarimetric Observations over the Ocean during the CLAMS Experiment, J. Atmos. Sci., 62, 1093-1117, 2005a.

Chowdhary, J., Cairns, B., Mishchenko, M., and Travis, L.: Using multi-angle multispectral photo-polarimetry of the NASA Glory mission to constrain optical properties of aerosols and clouds: results from four field experiments, Proc. SPIE, 5978, 59780G, 2005b.

Coddington, O., Pilewskie, P., Redemann, J., Platnick, S., Russell, P., Schmidt, K., Gore, W., Livingston, J., Wind, G., and Vukicevic, T.: Examining the impact of overlying aerosols on the retrieval of cloud optical properties from passive remote sensing, J. Geophys. Res., 115, D10211, doi:10.1029/2009JD012829, 2010.

Crounse, J. D., DeCarlo, P. F., Blake, D. R., Emmons, L. K., Campos, T. L., Apel, E. C., Clarke, A. D., Weinheimer, A. J., McCabe, D. C., Yokelson, R. J., Jimenez, J. L., and Wennberg, P. O.: Biomass burning and urban air pollution over the Central Mexican Plateau, Atmos. Chem. Phys., 9, 4929-4944, doi:10.5194/acp-9-4929-2009, 2009.

de Foy, B., Krotkov, N. A., Bei, N., Herndon, S. C., Huey, L. G., Martínez, A.-P., Ruiz-Suárez, L. G., Wood, E. C., Zavala, M., and Molina, L. T.: Hit from both sides: tracking industrial and volcanic plumes in Mexico City with surface measurements and $\mathrm{OMI} \mathrm{SO}_{2}$ retrievals during the MILAGRO field campaign, Atmos. Chem. Phys., 9, 9599-9617, doi:10.5194/acp-9-9599-2009, 2009.

De Graaf, M., Stammes, P., and Aben, E.: Analysis of reflectance spectra of UV-absorbing aerosol scenes measured by SCIAMACHY, J. Geophys. Res, 112, D02206, doi:10.1029/2006JD007249, 2007.

De Haan, J., Bosma, P., and Hovenier, J.: The adding method for multiple scattering calculations of polarized light, Astron. Astrophys., 183, 371-391, 1987.

Dinar, E., Riziq, A., Spindler, C., Erlick, C., Kiss, G., and Rudich, Y.: The complex refractive index of atmospheric and model humic-like substances (HULIS) retrieved by a cavity ring down aerosol spectrometer (CRD-AS), Faraday Discussions, 137, 279-295, 2008.

Doran, J. C., Barnard, J. C., Arnott, W. P., Cary, R., Coulter, R., Fast, J. D., Kassianov, E. I., Kleinman, L., Laulainen, N. S.,
Martin, T., Paredes-Miranda, G., Pekour, M. S., Shaw, W. J., Smith, D. F., Springston, S. R., and Yu, X.-Y.: The T1-T2 study: evolution of aerosol properties downwind of Mexico City, Atmos. Chem. Phys., 7, 1585-1598, doi:10.5194/acp-7-1585-2007, 2007.

Dubovik, O., Holben, B., Eck, T., Smirnov, A., Kaufman, Y., King, M., Tanré, D., and Slutsker, I.: Variability of absorption and optical properties of key aerosol types observed in worldwide locations, J. Atmos. Sci., 59, 590-608, 2002.

Elias, T., Cairns, B., and Chowdhary, J.: Surface optical properties measured by the airborne research scanning polarimeter during the CLAMS experiment, Remote Sensing of Clouds and the Atmosphere VIII, edited by: Schaefer, K., Comeron, A., Carleer, M. R., and Picard, R. H., Proc. SPIE,, 5235, 595-606, 2004.

Fast, J. D., de Foy, B., Acevedo Rosas, F., Caetano, E., Carmichael, G., Emmons, L., McKenna, D., Mena, M., Skamarock, W., Tie, X., Coulter, R. L., Barnard, J. C., Wiedinmyer, C., and Madronich, S.: A meteorological overview of the MILAGRO field campaigns, Atmos. Chem. Phys., 7, 2233-2257, doi:10.5194/acp-7-2233-2007, 2007.

Flowers, B. A., Dubey, M. K., Mazzoleni, C., Stone, E. A., Schauer, J. J., Kim, S.-W., and Yoon, S. C.: Optical-chemicalmicrophysical relationships and closure studies for mixed carbonaceous aerosols observed at Jeju Island; 3-laser photoacoustic spectrometer, particle sizing, and filter analysis, Atmos. Chem. Phys., 10, 10387-10398, doi:10.5194/acp-10-103872010, 2010.

Gatebe, C. K., Dubovik, O., King, M. D., and Sinyuk, A.: Simultaneous retrieval of aerosol and surface optical properties from combined airborne- and ground-based direct and diffuse radiometric measurements, Atmos. Chem. Phys., 10, 2777-2794, doi:10.5194/acp-10-2777-2010, 2010.

Goloub, P., Deuzé, J., Herman, M., and Fouquart, Y.: Analysis of the POLDER polarization measurements performed overcloud covers, IEEE Trans. Geosci. Remote Sens., 32, 78-88, 1994.

Goloub, P., Herman, M., Chepfer, H., Riedi, J., Brogniez, G., Couvert, P., and Sèze, G.: Cloud thermodynamical phase classification from the POLDER spaceborne instrument, J. Geophys. Res., 105(D11), 14747-14759, 2000.

Gonzalez, R. and Woods, R.: Digital Image Processing, Addison Wesley Publishing Company, New York, NY, USA, 209-213, 1992.

Grutter, M., Basaldud, R., Rivera, C., Harig, R., Junkerman, W., Caetano, E., and Delgado-Granados, H.: $\mathrm{SO}_{2}$ emissions from Popocatépetl volcano: emission rates and plume imaging using optical remote sensing techniques, Atmos. Chem. Phys., 8, 6655-6663, doi:10.5194/acp-8-6655-2008, 2008.

Hair, J. W., Caldwell, L. M., Krueger, D. A., and She, C.-Y.: HighSpectral-Resolution Lidar with Iodine-Vapor Filters: Measurement of Atmospheric-State and Aerosol Profiles, Appl. Opt., 40, 5280-5294, 2001.

Hair, J. W., Hostetler, C. A., Cook, A. L., Harper, D. B., Ferrare, R. A., Mack, T. L., Welch, W., Izquierdo, L. R., and Hovis, F. E.: Airborne High Spectral Resolution Lidar for profiling aerosol optical properties, Appl. Opt., 47, 6734-6752, 2008.

Hansen, J. and Travis, L.: Light scattering in planetary atmospheres, Space Sci. Rev., 16, 527-610., 1974.

Hasekamp, O. and Landgraf, J.: Retrieval of aerosol properties over land surfaces: capabilities of multiple-viewing-angle inten- 
sity and polarization measurements, Appl. Opt., 46, 3332-3344, 2007.

Hasekamp, O. P.: Capability of multi-viewing-angle photopolarimetric measurements for the simultaneous retrieval of aerosol and cloud properties, Atmos. Meas. Tech., 3, 839-851, doi:10.5194/amt-3-839-2010, 2010.

Haywood, J., Roberts, D., Slingo, A., Edwards, J., and Shine, K.: General circulation model calculations of the direct radiative forcing by anthropogenic sulfate and fossil-fuel soot aerosol, J. Climate, 10, 1562-1577, 1997.

Hoffer, A., Gelencser, A., Guyon, P., Kiss, G., Schmid, O., Frank, G., Artaxo, P., and Andreae, M.: Optical properties of humic-like substances(HULIS) in biomass-burning aerosols, Atmos. Chem. Phys., 6, 3563-3570, doi:10.5194/acp-6-3563-2006, 2006.

IPCC: Climate Change 2007 - The Physical Science Basis : Contribution of the Working Group I to the Fourth Assessment Report of the IPCC, Cambridge University Press, New York, NY, USA, 2007.

Kirchstetter, T., Novakov, T., and Hobbs, P.: Evidence that the spectral dependence of light absorption by aerosols is affected by organic carbon, J. Geophys. Res.-Atmos., 109, D21208, doi:10.1029/2004JD004999, 2004.

Knobelspiesse, K., Cairns, B., Schaaf, C., Schmid, B., and Román, M.: Surface BRDF estimation from an aircraft compared to MODIS and ground estimates at the Southern Great Plains site, J. Geophys. Res., 113, D20105, doi:10.1029/2008JD010062, 2008.

Knobelspiesse, K., Cairns, B., Ottaviani, M., Ferrare, R., Hair, J., Hostetler, C., Obland, M., Rogers, R., Redemann, J., Shinozuka, Y., Clarke, A., Freitag, S., Howell, S., Kapustin, V., and McNaughton, C.: Combined retrievals of boreal forest fire aerosol properties with a polarimeter and lidar, Atmos. Chem. Phys. Discuss., 11, 7909-7969, doi:10.5194/acpd-11-7909-2011, 2011.

Lewandowski, P. A., Eichinger, W. E., Holder, H., Prueger, J., Wang, J., and Kleinman, L. I.: Vertical distribution of aerosols in the vicinity of Mexico City during MILAGRO-2006 Campaign, Atmos. Chem. Phys., 10, 1017-1030, doi:10.5194/acp-10-10172010, 2010.

Lewis, K., Arnott, W. P., Moosmuller, H., and Wold, C. E.: Strong spectral variation of biomass smoke light absorption and single scattering albedo observed with a novel dual-wavelength photoacoustic instrument, J. Geophys. Res., 113, D16203, doi:10.1029/2007JD009699, 2008.

Litvinov, P., Hasekamp, O., Cairns, B., and Mishchenko, M.: Reflection models for soil and vegetation surfaces from multipleviewing angle photopolarimetric measurements, J. Quant. Spectrosc. Radiat. Transfer, 111, 529-539, 2010.

Livingston, J. M., Redemann, J., Russell, P. B., Torres, O., Veihelmann, B., Veefkind, P., Braak, R., Smirnov, A., Remer, L., Bergstrom, R. W., Coddington, O., Schmidt, K. S., Pilewskie, P., Johnson, R., and Zhang, Q.: Comparison of aerosol optical depths from the Ozone Monitoring Instrument (OMI) on Aura with results from airborne sunphotometry, other space and ground measurements during MILAGRO/INTEX-B, Atmos. Chem. Phys., 9, 6743-6765, doi:10.5194/acp-9-6743-2009, 2009.

Markwardt, C.: Non-linear Least Squares Fitting in IDL with MPFIT, Arxiv preprint arXiv:0902.2850, 2009.

Marley, N. A., Gaffney, J. S., Castro, T., Salcido, A., and Frederick, J.: Measurements of aerosol absorption and scattering in the
Mexico City Metropolitan Area during the MILAGRO field campaign: a comparison of results from the T0 and T1 sites, Atmos. Chem. Phys., 9, 189-206, doi:10.5194/acp-9-189-2009, 2009.

Miles, N., Verlinde, J., and Clothiaux, E.: Cloud droplet size distributions in low-level stratiform clouds, J. Atmos. Sci., 57, 295311, 2000.

Mishchenko, M. and Travis, L.: Gustav Mie and the evolving discipline of electromagnetic scattering by particles, B. Am. Meteorol. Soc., 89, 1853-1861, 2008.

Mishchenko, M., Cairns, B., Hansen, J., Travis, L., Burg, R., Kaufman, Y., Vanderlei Martins, J., and Shettle, E.: Monitoring of aerosol forcing of climate from space: analysis of measurement requirements, J. Quant. Spectrosc. Radiat. Transfer, 88, 149-161, 2004.

Mishchenko, M., Cairns, B., Kopp, G., Schueler, C., Fafaul, B., Hansen, J., Hooker, R., Itchkawich, T., Maring, H., and Travis, L.: Accurate monitoring of terrestrial aerosols and total solar irradiance: introducing the Glory mission, B. Am. Meteorol. Soc, 88, 677-691, 2007a.

Mishchenko, M., Geogdzhayev, I., Cairns, B., Carlson, B., Chowdhary, J., Lacis, A., Liu, L., Rossow, W., and Travis, L.: Past, present, and future of global aerosol climatologies derived from satellite observations: A perspective, J. Quant. Spectrosc. Radiat. Transfer, 106, 325-347, 2007b.

Mishchenko, M., Geogdzhayev, I., Liu, L., Lacis, A., Cairns, B., and Travis, L.: Toward unified satellite climatology of aerosol properties: What do fully compatible MODIS and MISR aerosol pixels tell us?, J. Quant. Spectrosc. Radiat. Transfer, 2009.

Molina, L. T., Madronich, S., Gaffney, J. S., Apel, E., de Foy, B., Fast, J., Ferrare, R., Herndon, S., Jimenez, J. L., Lamb, B., Osornio-Vargas, A. R., Russell, P., Schauer, J. J., Stevens, P. S., Volkamer, R., and Zavala, M.: An overview of the MILAGRO 2006 Campaign: Mexico City emissions and their transport and transformation, Atmos. Chem. Phys., 10, 8697-8760, doi:10.5194/acp-10-8697-2010, 2010.

Moré, J.: The Levenberg-Marquardt Algorithm: Implementation and Theory, in: Lecture Notes in Mathematics: Numerical Analysis, edited by Watson, G. A., Proceedings of the Biennial Conference Held at Dundee, Springer-Verlag, Berlin, Germany, 630, 105-116, 1977.

Paredes-Miranda, G., Arnott, W. P., Jimenez, J. L., Aiken, A. C., Gaffney, J. S., and Marley, N. A.: Primary and secondary contributions to aerosol light scattering and absorption in Mexico City during the MILAGRO 2006 campaign, Atmos. Chem. Phys., 9, 3721-3730, doi:10.5194/acp-9-3721-2009, 2009.

Pilewskie, P., Pommier, J., Bergstrom, R., Gore, W., Howard, S., Rabbette, M., Schmid, B., Hobbs, P., and Tsay, S.: Solar spectral radiative forcing during the southern african regional science initiative, J. Geophys. Res, 108, 8486 doi:10.1029/2002JD002411, 2003.

Redemann, J., Zhang, Q., Livingston, J., Russell, P., Shinozuka, Y., Clarke, A., Johnson, R., and Levy, R.: Testing aerosol properties in MODIS Collection 4 and 5 using airborne sunphotometer observations in INTEX-B/MILAGRO, Atmos. Chem. Phys., 9, 8159-8172, doi:10.5194/acp-9-8159-2009, 2009.

Rogers, R. R., Hair, J. W., Hostetler, C. A., Ferrare, R. A., Obland, M. D., Cook, A. L., Harper, D. B., Burton, S. P., Shinozuka, Y., McNaughton, C. S., Clarke, A. D., Redemann, J., Russell, P. B., Livingston, J. M., and Kleinman, L. I.: NASA LaRC airborne 
high spectral resolution lidar aerosol measurements during MILAGRO: observations and validation, Atmos. Chem. Phys., 9, 4811-4826, doi:10.5194/acp-9-4811-2009, 2009

Schmidt, K. S., Pilewskie, P., Bergstrom, R., Coddington, O., Redemann, J., Livingston, J., Russell, P., Bierwirth, E., Wendisch, M., Gore, W., Dubey, M. K., and Mazzoleni, C.: A new method for deriving aerosol solar radiative forcing and its first application within MILAGRO/INTEX-B, Atmos. Chem. Phys., 10, 78297843, doi:10.5194/acp-10-7829-2010, 2010.

Schulz, M., Textor, C., Kinne, S., Balkanski, Y., Bauer, S., Berntsen, T., Berglen, T., Boucher, O., Dentener, F., Guibert, S., Isaksen, I. S. A., Iversen, T., Koch, D., Kirkevåg, A., Liu, X., Montanaro, V., Myhre, G., Penner, J. E., Pitari, G., Reddy, S., Seland, ., Stier, P., and Takemura, T.: Radiative forcing by aerosols as derived from the AeroCom present-day and pre-industrial simulations, Atmos. Chem. Phys., 6, 5225-5246, doi:10.5194/acp-65225-2006, 2006.

Stohl, A., Forster, C., Frank, A., Seibert, P., and Wotawa, G.: Technical note: The Lagrangian particle dispersion model FLEXPART version 6.2, Atmos. Chem. Phys., 5, 2461-2474, doi:10.5194/acp-5-2461-2005, 2005.

Sun, H., Biedermann, L., and Bond, T.: Color of brown carbon: A model for ultraviolet and visible light absorption by organic carbon aerosol, Geophys. Res. Lett., 34, L17813, doi:10.1029/2007GL029797, 2007. van de Hulst, H.: Light scattering by small particles, Dover Pubns, 1981.

Waquet, F., Cairns, B., Knobelspiesse, K., Chowdhary, J., Travis, L., Schmid, B., and Mishchenko, M.: Polarimetric remote sensing of aerosols over land, J. Geophys. Res, 114, D01206, doi:10.1029/2008JD010619, 2009a.

Waquet, F., Riedi, J., Labonnote, L., Goloub, P., Cairns, B., Deuzé, J., and Tanré, D.: Aerosol Remote Sensing over Clouds Using A-Train Observations, J. Atmos. Sci., 66, 2468-2480, 2009b.

Winker, D., Pelon, J., and McCormick, M.: The CALIPSO mission: Spaceborne lidar for observation of aerosols and clouds, Int. Society for Optical Engineering, 4893, 1-11, 2003.

Winker, D., Hostetler, C., Vaughan, M., and Omar, A.: CALIOP Algorithm Theoretical Basis Document, Part I, Tech. Rep. PCSCI-202 Part I, NASA Langley Research Center, 2006.

Yu, X.-Y., Cary, R. A., and Laulainen, N. S.: Primary and secondary organic carbon downwind of Mexico City, Atmos. Chem. Phys., 9, 6793-6814, doi:10.5194/acp-9-6793-2009, 2009. 